\title{
A dinâmica inflacionária no Brasil de 2000 a 2009: uma abordagem multissetorial *
}

\author{
Leandro Gomes ** \\ Fabio Freitas ${ }^{* * *}$
}

\begin{abstract}
Resumo
O objetivo deste trabalho é analisar, de uma perspectiva multissetorial, o processo inflacionário brasileiro no período 2000-2009. Para tanto, desenvolvemos uma metodologia de decomposição estrutural a ser aplicada ao modelo de preços associado à Matriz Insumo-Produto. Os resultados são analisados com base na hipótese de que em condições normais de funcionamento de uma economia de mercado, a inflação é predominantemente causada pela majoração dos custos de produção. A análise do período 2001-2009 é dividida em três subperíodos. No primeiro, 2001-2003, a variável central para explicar a inflação brasileira é a taxa nominal de câmbio. No segundo, 2004-2005, aumenta a importância do preço das commodities e a influência da dinâmica salarial. No terceiro, 2006-2009, a principal causa do processo inflacionário passa a ser o custo unitário do trabalho. Associada à mudança na trajetória das variáveis distributivas, a importância do setor de serviços na explicação da inflação brasileira aumenta.
\end{abstract}

Palavras-chave: Inflação de custo; Decomposição estrutural; Modelo de preços da matriz insumo-produto.

\section{Abstract \\ Brazilian inflationary dynamics from 2000 to 2009: a multisector approach}

This work aims to analyze, from a multisector point of view, the Brazilian inflationary process between 2000 and 2009. In order to do so, we present a structural decomposition analysis methodology to be applied to the InputOutput Price Model. Based on the assumption that under normal conditions of a market economy inflation is mainly caused by the increase in production costs, we evaluate the results for the Brazilian economy during the period 20012009. The period is divided into three phases. In the first, 2001-2003, the major cause of Brazilian inflation is the nominal exchange rate. The second, 2004-2005, sees increases in the importance of commodity prices and wages. In the last phase, 2006-2009, labor cost exerts the most important influence on the inflation rate, and due to the behavior of income distributive variables, the service sector became an important factor in the explanation of the inflation rate in the Brazilian economy.

Keywords: Cost push inflation; Structural decomposition analysis; Input-output price model matrix.

JEL E 31.

\section{Introdução}

Ao longo do período 2000-2009, a inflação brasileira se comportou de modo heterogêneo. Esse período foi marcado por elevado crescimento dos preços internacionais das commodities, volatilidade da taxa nominal de câmbio e diferentes fases da influência do custo

\footnotetext{
${ }^{*}$ Artigo recebido em 18 de janeiro de 2018 e aprovado em 1 de abril de 2019.

${ }^{* *}$ Professor do Instituto Três Rios da Universidade Federal Rural do Rio de Janeiro, Três Rios, RJ, Brasil. E-mail: leandrogomes.ie@uol.com.br. ORCiD: https://orcid.org/0000-0002-3659-4125.

${ }^{* * *}$ Professor do Instituto de Economia da Universidade Federal do Rio de Janeiro (IE/UFRJ), Rio de Janeiro, RJ, Brasil. E-mail: fabio@ie.ufrj.br. ORCiD: https://orcid.org/0000-0001-8499-111X.
} 
unitário do trabalho sobre o processo inflacionário brasileiro. De 2001 a 2003, a taxa de inflação brasileira foi alta, com média de dois dígitos, e a partir de 2004, ela começa a cair. Esta queda é mais acentuada a partir de 2006. Adicionalmente, os fatores responsáveis pela dinâmica inflacionária foram distintos ao longo da década.

Numa perspectiva heterodoxa, a extensão do princípio da demanda efetiva para o longo prazo e o seu uso para explicar o crescimento econômico leva ao entendimento de que a capacidade produtiva da economia é endógena. Uma consequência lógica desta endogeneidade é a compreensão de que, em condições normais de funcionamento de uma economia de mercado, a inflação é um fenômeno predominantemente causado pela majoração dos custos de produção. Existe uma literatura razoavelmente consolidada que interpreta o processo inflacionário na primeira década do século a partir dessa perspectiva. O objetivo desse trabalho é complementar esse tipo de explicação para o processo inflacionário no período, introduzindo a dimensão multissetorial.

Assim, em primeiro lugar, é apresentada a metodologia de decomposição estrutural aplicada ao modelo Insumo-Produto de preços. Em seguida, são interpretados os resultados da aplicação desta metodologia com o objetivo de explicar o processo inflacionário brasileiro, no período 2000-2009, à luz da chamada Abordagem do Excedente, partindo do entendimento de que, em condições normais de funcionamento de uma economia capitalista, a inflação é predominantemente de custos. Na descrição do processo inflacionário, é abordada a relação entre os fatores responsáveis pela dinâmica inflacionária e o comportamento das variáveis distributivas chaves.

$\mathrm{Na}$ análise, são avaliados os efeitos associados à decomposição estrutural, que envolvem modificações nos coeficientes técnicos de produção, e nas variáveis distributivas associadas à formação de preço, como taxa de câmbio, custo unitário do trabalho e margens de lucro.

A base de dados usada na análise consiste no Sistema de Contas Nacionais (SCN), disponibilizado pelo Instituto Brasileiro de Geografia e Estatística (IBGE). Mais precisamente, no modelo de preços que pode ser construído a partir da base de dados da Matriz InsumoProduto. Uma dificuldade associada a essa base de dados é a grande defasagem temporal com a qual ela é disponibilizada e a descontinuidade das matrizes (e das tabelas auxiliares associadas) que são produzidas apenas uma vez a cada cinco anos. O trabalho de Neves (2013) preenche a lacuna associada à descontinuidade, uma vez que o autor atualiza as matrizes (e as tabelas auxiliares) de 2001 a 2009 tanto a preços correntes como a preços constantes, dentro dos parâmetros do Sistema de Contas Nacionais Referência 2000, para os anos em que a MIP não é disponibilizada pelo IBGE.

Do ponto de vista metodológico, este trabalho avança na aplicação da decomposição estrutural, pois abrange um campo novo, associado ao modelo de preços da Matriz InsumoProduto, uma vez que tradicionalmente esse exercício é realizado para o modelo de quantidades. Adicionalmente, contribui para a discussão dos determinantes da inflação 
brasileira nos anos 2000, pois aplica uma metodologia inédita na estimação do impacto das variáveis distributivas chaves do sistema de preços, aproveitando uma base de dados integrada que é o Sistema de Contas Nacionais.

O trabalho está dividido em seis seções além desta introdução. Na seção 1 é apresentada a fundamentação teórica. A seção 2 apresenta a metodologia de decomposição estrutural da taxa de inflação e das margens de lucro. A seção 3 explica o critério utilizado na separação das atividades em setores com preço internacional e setores com preço doméstico. $\mathrm{Na}$ seção 4 é descrito o processo inflacionário brasileiro a partir dos resultados da decomposição estrutural e do arcabouço teórico utilizado. A seção 5 apresenta os resultados da decomposição das margens de lucro. Na última seção é exposta a conclusão.

\section{0 processo inflacionário}

Podemos dizer que em uma economia aberta existem dois "tipos" de preços, ou dois processos de formação de preço. O primeiro está associado aos bens que seguem um processo doméstico de precificação e depende, predominantemente, da evolução dos custos de produção; enquanto o segundo está relacionado com os bens que seguem um preço de referência internacional, que depende do preço dos próprios bens em moeda de referência internacional e da taxa nominal de câmbio (ver Aukrust, 1977; Frisch, 1977 e Edgren et al., 1969).

Nesse sentido, como uma primeira aproximação, podemos representar a taxa de inflação como:

$$
\begin{gathered}
\pi_{\mathrm{t}}^{\mathrm{D}}=\mathrm{x} \cdot \pi_{\mathrm{t}-1}+\mathrm{b}\left(\mathrm{Y}_{\mathrm{t}}-\mathrm{Y}_{\mathrm{t}}^{*}\right)+\mathrm{h}_{\mathrm{t}} \\
\pi_{\mathrm{t}}^{\mathrm{I}}=\mathrm{g}_{\mathrm{e}_{\mathrm{t}}}+\pi_{\mathrm{t}}^{*}
\end{gathered}
$$

Onde: $\mathrm{x}$ é o coeficiente de inércia, $\mathrm{Y}^{*} \mathrm{o}$ produto potencial e $\mathrm{Y}$ o produto efetivo. $\mathrm{h}_{\mathrm{t}}$ representa um choque de custos, $\pi_{\mathrm{t}-1}$ corresponde à taxa de inflação do período anterior, $\pi^{*}$, a taxa de inflação em moeda estrangeira dos bens que seguem um preço de referência internacional, $\underline{\mathrm{e}}$ representa a taxa nominal de câmbio e $\mathrm{g}_{\mathrm{e}_{\mathrm{t}}}$, a taxa de crescimento da taxa nominal de câmbio.

A equação (1) mostra que a taxa de inflação corrente dos bens que seguem um processo doméstico de precificação ( $\pi_{\mathrm{t}}^{\mathrm{D}}$ ) depende, a princípio, do componente de inércia da inflação, do hiato de produto (diferença entre o produto efetivo e o potencial) e de mudanças nos componentes de custos ${ }^{1}$. A equação (2) mostra que a inflação para os bens que seguem um processo internacional de precificação $\left(\pi_{\mathrm{t}}^{\mathrm{I}}\right)$ depende tanto da trajetória da taxa nominal de câmbio, como do preço dos bens no mercado internacional.

(1) Para uma discussão sobre as consequências distributivas da perseguição de uma meta de inflação em uma perspectiva estruturalista, ver Barbosa-Filho (2014). 
Podemos expressar a taxa de inflação corrente da economia como:

$$
\pi_{\mathrm{t}}=\mathrm{d} \cdot \pi_{\mathrm{t}}^{\mathrm{D}}+(1-\mathrm{d}) \cdot \pi_{\mathrm{t}}^{\mathrm{I}}
$$

Onde: d representa a participação dos bens com preço doméstico no conjunto da economia, e (1-d), dos bens com preço internacional.

Assim, a taxa de inflação corrente pode ser exposta como:

$$
\pi_{\mathrm{t}}=\mathrm{dx} \pi_{\mathrm{t}-1}+\mathrm{db}\left(\mathrm{Y}_{\mathrm{t}}-\mathrm{Y}_{\mathrm{t}}^{*}\right)+\mathrm{d} \cdot \mathrm{h}_{\mathrm{t}}+(1-\mathrm{d}) \mathrm{g}_{\mathrm{e}_{\mathrm{t}}}+(1-\mathrm{d}) \cdot \pi_{\mathrm{t}}^{*}
$$

Para os bens com preço doméstico, os fatores que determinam o preço de oferta são a produtividade do trabalho, o salário nominal, as margens de lucro, a taxa de câmbio e o preço internacional das commodities. Os custos de produção acrescidos do mark-up que caracteriza cada setor da atividade econômica determinam o preço de oferta deste tipo de bem, como ficará evidente mais adiante.

Partindo da ideia de que o processo de crescimento é fundamentalmente liderado pela demanda e de que o investimento segue a lógica do princípio do ajustamento do estoque de capital, ${ }^{2}$ podemos argumentar que a capacidade produtiva da economia é determinada endogenamente pelo ritmo de crescimento da demanda agregada ${ }^{3,4}$. Uma consequência disto é que o hiato do produto tende a desaparecer na medida em que o produto potencial se ajusta no longo prazo ao nível de demanda agregada. Com isso o segundo termo da equação (4) acima tende a ser nulo, fazendo com que a demanda agregada não seja uma fonte de pressão permanente sobre a inflação no longo prazo, isto é, ela não afeta a taxa de inflação sistematicamente, período após período. A contrapartida disto é que o núcleo da inflação é

(2) Esta descrição do processo de crescimento está baseada no modelo do Supermultiplicador Sraffiano. Para uma análise deste tipo de modelo veja Serrano (1995a, 1995b), Freitas e Serrano (2007, 2015) e Serrano e Freitas (2017). Recentemente alguns autores Kaleckianos têm utilizado uma versão do modelo, nesse sentido confira Lavoie (2016) e Allain (2015). Para uma análise do processo inflacionário com base neste tipo de abordagem e que salienta a endogeneidade do produto potencial no longo prazo, ver Serrano (2006).

(3) Este argumento está baseado na hipótese de que a principal restrição de oferta ao crescimento da economia brasileira é dada pelo estoque de capital disponível. A presença de um grande excedente de mão de obra (Lewis, 1954), somada a mecanismos que tendem a tornar a oferta de trabalho endógena, fazem com que a força de trabalho não seja uma restrição relevante para o processo de crescimento na economia brasileira. Dentre tais mecanismos podemos citar o aumento da taxa de participação da força de trabalho nas fases expansivas do ciclo econômico, mudanças nas regras de imigração com o objetivo de induzir o aumento da oferta de mão de obra e, até mesmo, o aumento da taxa de natalidade em momentos de maior prosperidade. Finalmente, o próprio crescimento da produtividade do trabalho tende a seguir o crescimento da economia, atenuando as pressões sobre o mercado de trabalho.

(4) Nesta perspectiva, o principal obstáculo ao crescimento liderado pela demanda na economia brasileira é a restrição de balanço de pagamentos. Com origem na tradição estruturalista latino-americana (ver Prebisch, 1949), a restrição de balanço de pagamentos é uma restrição financeira relacionada ao fato de que a economia brasileira não emite moeda que seja meio de pagamento internacional tal como o dólar americano nos dias de hoje. A única forma de saldar seus compromissos com o exterior é a obtenção de divisas (dólares) pode meio de suas transações reais e financeiras com o resto do mundo. Assim, em situações de escassez de divisas a economia pode ser forçada a reduzir seu ritmo de crescimento e/ou desvalorizar a taxa de câmbio. Neste último caso teríamos uma importante fonte de pressão inflacionária. Para uma análise da hipótese de restrição externa ver, entre outros, Medeiros e Serrano (1999) e para uma análise do papel desta restrição no caso da economia brasileira ver Medeiros e Serrano (2001). 
explicado pela evolução dos custos de produção ao longo do tempo e não por quadros de excesso de demanda. Essa interpretação é distinta da oferecida pelo arcabouço teórico subjacente ao modelo de metas de inflação.

Para podermos discutir melhor o processo inflacionário, que consiste na taxa de crescimento do nível de preços, é preciso primeiro entender como o nível de preços é explicado. Utilizando a especificação adotada por Gomes (2016), podemos expressar o preço de produção da seguinte maneira:

$$
\mathrm{P}_{\mathrm{t}}=\mu_{\mathrm{t}} \cdot \mathrm{C}_{\mathrm{t}-1}
$$

Onde: $\mathrm{P}_{\mathrm{t}}=$ preço no período corrente; $\mu_{\mathrm{t}}=$ mark-up no período corrente; $\mathrm{C}_{(\mathrm{t}-1)}=$ custo unitário no período anterior 5 .

$$
\mathrm{P}_{\mathrm{t}-1}=\mu_{\mathrm{t}-1} \cdot \mathrm{C}_{\mathrm{t}-2}
$$

Os preços são formados com base em um mark-up sobre os custos unitários observados do período anterior. Este mark-up é reflexo das características de cada setor e do processo de concorrência capitalista ${ }^{6}$.

$$
\left(1+\pi_{t}^{D}\right) \cdot P_{t-1}=\left(1+g_{\mu_{t}}\right) \cdot \mu_{t-1} \cdot\left(1+g_{c}(t-1)\right) \cdot C_{t-2}
$$

Onde: $\pi_{t}{ }^{D}=$ taxa de inflação dos bens com preço doméstico em $t, g_{\mu_{t}}=$ taxa de crescimento do mark-up em $\mathrm{t}$ e $\mathrm{g}_{\mathrm{c}_{(\mathrm{t}-1)}}=$ taxa de crescimento dos custos em $\mathrm{t}-1$.

O custo unitário depende, respectivamente, do consumo intermediário de bens com preço doméstico (a.P), do consumo intermediário dos bens com preço internacional (m.e.P*) e do custo unitário do trabalho, ou seja, das contribuições patronais sobre a folha de pagamento $\left(\mathrm{t}_{\mathrm{w}}\right)$, do salário nominal $(\mathrm{w})$ e da produtividade do trabalho (b).

$$
C_{t}=\left[\left(a_{t} \cdot P_{t}+m_{t} \cdot e_{t} \cdot P_{t}^{*}\right)\left(1+T_{t}\right)\right]+\left[\frac{w_{t}\left(1+t_{w_{t}}\right)}{b_{t}}\right]
$$

Onde: $\mathrm{a}=$ coeficiente técnico dos insumos com preço doméstico, $\mathrm{m}=$ coeficiente técnico dos insumos com preço internacional, $\mathrm{P}^{*}=$ preço dos bens com preço internacional.

Os impostos sobre produtos (T) também afetam o preço, pois também compõem os custos. Para facilitar a compreensão do modelo e, principalmente, tornar mais explícitos alguns resultados, a expressão que denota o custo unitário será modificada.

$$
\mathrm{C}_{\mathrm{t}}=\tau_{\mathrm{t}} \cdot\left[\left(\mathrm{a}_{\mathrm{t}} \cdot \mathrm{P}_{\mathrm{t}}+\mathrm{m}_{\mathrm{t}} \cdot \mathrm{e}_{\mathrm{t}} \cdot \mathrm{P}_{\mathrm{t}}^{*}\right)+\left(\frac{\mathrm{w}_{\mathrm{t}}}{\mathrm{b}_{\mathrm{t}}}\right)\right]
$$

(5) Na discussão sobre a plausibilidade (racionalidade econômica) da hipótese de conflito distributivo é fundamental que a análise seja feita com base no chamado custo histórico. Ver Serrano (2010).

(6) Como discutido acima, associado à tendência de gravitação dos preços em torno do preço de oferta, temos o processo de migração do capital, equalizando as rentabilidades. Os determinantes do mark-up serão discutidos mais à frente. 


$$
\begin{gathered}
\tau_{t}=1+\left[\frac{\left(a_{t} \cdot P_{t}+m_{t} \cdot e_{t} \cdot P_{t}^{*}\right)}{\left(a_{t} \cdot P_{t}+m_{t} \cdot e_{t} \cdot P^{*}{ }_{t}\right)+\left(\frac{w_{t}}{b_{t}}\right)} \cdot T_{t}\right. \\
\left.+\frac{\left(\frac{w_{t}}{b_{t}}\right)}{\tau_{t} \cdot\left[\left(a_{t} \cdot P_{t}+m_{t} \cdot e_{t} \cdot P^{*}{ }_{t}\right)+\left(\frac{w_{t}}{b_{t}}\right)\right.} \cdot t_{w_{t}}\right]
\end{gathered}
$$

A variável $\tau$ funciona como uma espécie de mark-up relacionado ao impacto que os impostos incidentes tanto sobre o consumo intermediário nacional e importado como sobre o custo unitário do trabalho exercem sobre os custos de produção (unitários). A alíquota do imposto depende da tributação sobre o consumo intermediário, da participação do consumo intermediário no custo unitário, da tributação sobre o custo unitário do trabalho e da participação do custo unitário do trabalho no custo unitário do produto. Qualquer modificação na tributação afeta os custos de produção. Assim como, se a alíquota for distinta entre o consumo intermediário e o custo unitário do trabalho, qualquer mudança de participação deles sobre o custo unitário (total) também afetará a alíquota final que vigora sobre o bem.

Supondo que o coeficiente associado ao consumo intermediário importado (m) e doméstico (a) se mantém inalterado, a partir de (10) podemos deduzir a taxa de variação dos custos, que pode ser apresentada de maneira aproximada como:

$$
g_{C_{t}}=g_{\tau_{t}}+\sigma_{a} \cdot \pi^{D}{ }_{t}+\sigma_{m} \cdot\left(\pi^{*}{ }_{t}+g_{e_{t}}\right)+\sigma_{w} \cdot\left(g_{w_{t}}-g_{b_{t}}\right)
$$

Onde: $\sigma_{\mathrm{a}}=$ participação do consumo intermediário de bens com preço doméstico no custo no período anterior; $\sigma_{\mathrm{m}}=$ participação do consumo intermediário de bens com preço internacional (em moeda doméstica) no custo no período anterior; $\sigma_{\mathrm{w}}=$ participação do custo unitário do trabalho no custo no período anterior; $\pi^{\mathrm{D}}=$ taxa de inflação do consumo intermediário dos bens com preço doméstico; $\pi^{*}=$ taxa de inflação do consumo intermediário dos bens com preço internacional em moeda estrangeira; $g_{\tau}=$ taxa de crescimento da tributação, $g_{w}=$ taxa de crescimento dos salários nominais e $\mathrm{g}_{\mathrm{b}}=$ taxa de crescimento da produtividade do trabalho.

Como os preços são formados por um mark-up sobre os custos de produção do período anterior, temos:

$$
\begin{gathered}
\pi_{\mathrm{t}}^{\mathrm{D}}=\mathrm{g}_{\mu_{\mathrm{t}}}+\mathrm{g}_{\tau_{(\mathrm{t}-1)}}+\sigma_{\mathrm{a}} \cdot \pi_{(\mathrm{t}-1)}^{\mathrm{D}}+\sigma_{\mathrm{m}} \cdot\left(\mathrm{g}_{\mathrm{e}_{(\mathrm{t}-1)}}+\pi_{(\mathrm{t}-1)}^{*}\right) \\
+\sigma_{\mathrm{w}} \cdot\left(\mathrm{g}_{w_{(\mathrm{t}-1)}}+\mathrm{g}_{\mathrm{b}_{(\mathrm{t}-1)}}\right)
\end{gathered}
$$

Portanto, para os bens que seguem um processo doméstico de precificação, a evolução dos custos, como impostos sobre produtos, preço em moeda doméstica dos bens que seguem um processo de precificação internacional e do custo unitário do trabalho (salário nominal e produtividade), e do mark-up setorial explicam a majoração dos preços.

O segundo "tipo" de preço diz respeito aos bens nos quais os preços são formados internacionalmente, como, por exemplo, o minério de ferro. O preço dessas mercadorias 
depende da técnica dominante, dos salários e da taxa de juros, expressos em moeda de circulação internacional (Dólar), nos países que produzem estes produtos usando a técnica dominante ${ }^{7}$. A cotação no mercado doméstico depende da taxa nominal de câmbio (e) e do preço praticado no mercado internacional $\left(\mathrm{P}^{*}\right)$. Nesse caso, o preço que exerce o poder de gravitação é o preço que vigora no mercado internacional, em unidades do padrão monetário doméstico.

Aqui cabe uma qualificação importante. No caso desses bens, não nos parece muito razoável imaginar que uma alteração do preço internacional em moeda local (e.P*) não afetará o preço praticado pelos fornecedores domésticos desses bens. Como consequência da tentativa de equalizar as rentabilidades, o preço praticado no mercado nacional por produtores domésticos tende a igualar-se ao preço internacional. Mesmo que no mercado nacional, a maior parte da oferta seja suprida por produtores domésticos, os produtos que apresentam a característica de formação de preço no mercado internacional, como, notadamente, é o caso das commodities, tendem a acompanhar o comportamento observado da cotação da mercadoria na economia mundial. Caso os produtores praticassem um preço de mercado menor do que o preço de referência internacional, eles desperdiçariam rentabilidade, uma vez que poderiam exportar para uma demanda infinitamente elástica, afinal, praticam preço inferior ao preço de mercado. No caso da queda da cotação internacional, imaginar que os produtores nacionais manteriam o preço constante também nos parece improvável, uma vez que todos os compradores poderiam importar o bem mais barato de uma oferta, a princípio, também infinitamente elástica (ou simplesmente muito elástica). Assim, sempre que um bem apresenta a característica de possuir um preço de referência internacional, a tendência de longo prazo é que o preço praticado no mercado doméstico seja o preço que vigora no mercado internacional convertido para moeda local (e.P*).

A consequência distributiva de acompanhar um preço de referência internacional, e do consequente descolamento entre o preço de mercado e os custos de produção (unitários), é que o mark-up é determinado endogenamente. A formação de preço não é realizada acrescentando um mark-up sobre os custos de produção, na verdade, o mark-up é "residual", determinado pela diferença (ou mais precisamente, pela razão) entre o preço em moeda local do bem e o custo de produção (do período corrente) $)^{8}$.

$$
\begin{gathered}
P_{t}=e_{t} \cdot P_{t}^{*}=\mu_{t} \cdot C_{t} \\
\mu_{t}=\frac{e_{t} \cdot P_{t}^{*}}{C_{t}}
\end{gathered}
$$

Se o preço de oferta dos produtores domésticos for menor que o preço de mercado, eles possuem competitividade para produzir e vender no mercado doméstico e internacional.

(7) Podem, portanto, sofrer influência nula, ou quase nula, da demanda por eles, em determinado país específico.

(8) Para haver racionalidade econômica na hipótese de conflito distributivo nos setores com preço internacional, não há necessidade de trabalhar com o custo defasado. Na verdade, as margens de lucro para os bens com preço internacional são margens reais, explicitando a disputa distributiva. Ver Gomes (2016). 
Eventuais excessos de demanda podem ser supridos pelas importações. Para que a demanda, ou a oferta, doméstica afetem os preços internacionais é preciso que a economia do país seja "grande". Nesse caso, a oferta internacional não seria tão elástica, a determinado preço de mercado, como discutida acima, devido ao tamanho da economia doméstica. Note que ainda assim, continua valendo a proposição de que o preço no mercado interno acompanha a cotação internacional. Além disso, uma contração da demanda agregada com o objetivo de gerar algum efeito, mesmo que pequeno, sobre os preços dessas mercadorias pode ser inócuo, pois alguma mudança no plano internacional, como uma política expansiva em outro país, pode anular esse efeito.

Retomando a equação (2):

$$
\pi_{\mathrm{t}}^{\mathrm{I}}=\mathrm{g}_{\mathrm{e}}+\pi_{\mathrm{t}}^{*}
$$

Ao invés da evolução do nível de preço ser determinada pela evolução dos custos de produção, é a evolução das margens de lucro que é determinada pela evolução dos custos (ver Edgren et al, 1969). A evolução do preço dos bens com preço internacional depende exclusivamente da taxa de câmbio e do preço de referência internacional. Sendo assim, podemos obter uma equação para explicar as variações nas margens de lucro, tal como:

$$
\begin{gathered}
g_{\mu_{t}}=g_{e_{t}}+\pi_{t}^{*}-g_{C_{t}} \\
g_{\mu_{t}}=g_{e_{t}}+\pi_{t}^{*}-\left[g_{\tau_{t}}+\sigma_{a} \cdot \pi_{t}^{D}+\sigma_{m} \cdot\left(g_{e_{t}}+\pi_{t}^{*}\right)+\sigma_{w} \cdot\left(g_{w_{t}}-g_{b_{t}}\right)\right] \\
g_{\mu_{t}}=\left(1-\sigma_{m}\right) \cdot\left(g_{e_{t}}+\pi_{t}^{*}\right)-g_{\tau_{t}}-\sigma_{a} \cdot \pi^{D}-\sigma_{w} \cdot\left(g_{w_{t}}-g_{b_{t}}\right)
\end{gathered}
$$

Podemos observar que o encarecimento dos bens com preço internacional em moeda doméstica apresenta dois efeitos: o de elevação do preço em moeda doméstica do bem final e o de aumento dos custos de produção. Como a produção é realizada com a aquisição de insumos precificados internacionalmente, a desvalorização cambial e/ou o aumento da cotação internacional elevam o custo de produção. Porém, como podemos observar pela equação (15), o crescimento do preço em moeda doméstica do bem final é maior do que o aumento dos custos de produção, uma vez que $\sigma_{\mathrm{m}}$ é menor do que uma unidade. $\mathrm{O}$ aumento do preço em moeda local dos bens que seguem um valor de referência mundial, mesmo pressionando os custos, expande das margens de lucro.

Enquanto para os bens com preço doméstico, os custos determinam a evolução do preço do bem final, para os bens com preço internacional, a trajetória dos custos afeta a evolução da margem de lucro.

\section{A metodologia de decomposição estrutural}

A metodologia utilizada para analisar a dinâmica inflacionária brasileira de 2000 a 2009 foi a decomposição estrutural aplicada ao Modelo Insumo-Produto (I-O) de Preços. A construção do Modelo I-O de Preços parte dos dados presentes na Matriz Insumo-Produto (MIP). Como mostram Miller e Blair (2009), é possível medir o impacto que cada um dos 
componentes do custo de produção exerce sobre o preço de cada setor de atividade. A aplicação da decomposição estrutural ao Modelo de Preços nos permite realizar a decomposição (estrutural) da taxa de crescimento do nível de preços, ou seja, a decomposição da taxa de inflação. O objetivo é isolar o efeito de cada um dos elementos de custo para poder avaliar a influência de cada um deles no processo inflacionário.

A metodologia da decomposição estrutural da taxa de inflação a partir do Modelo de Preços está presente em Gomes (2016). No referido trabalho, também estão registradas todas as dificuldades para a execução da decomposição e algumas diferenças em relação à decomposição do modelo de quantidades.

O objetivo do presente trabalho é mostrar o formato final de execução da decomposição para poder, em seguida, discutir o processo inflacionário no Brasil.

A partir de Gomes (2016), podemos decompor a taxa de inflação como:

$$
\pi=A \pi+\widehat{\pi}+\hat{\mathrm{q}}+\widehat{\mathrm{ml}}+\hat{\mathrm{r}}+\hat{\mathrm{t}}+\widehat{\mathrm{m}}+\hat{\mathrm{s}}
$$

onde: A é a matriz (transposta) de coeficientes técnicos domésticos; $\boldsymbol{\pi}$ é o vetor ${ }^{9}$ coluna com as taxas de inflação de cada atividade; $\widehat{\boldsymbol{\pi}}$ é um vetor que capta a mudança de preços relativos do consumo intermediário nacional; $\widehat{\mathbf{q}}$, é um vetor que capta a mudança de volume relativo do consumo intermediário nacional; $\hat{\mathbf{t}}$ é um vetor que reflete a influência dos impostos sobre produtos; $\widehat{\mathbf{m l}}$ é um vetor que capta a influência da variação das margens de lucro; $\widehat{\mathbf{r}}$ é um vetor que reflete a influência do custo unitário do trabalho, do rendimento misto e dos demais impostos livres de subsídios; $\widehat{\mathbf{m}}$ é um vetor com a taxa de inflação do consumo intermediário importado e com a mudança de volume relativo de cada atividade; e, finalmente, $\widehat{\mathbf{s}}$ é um vetor com termos de interação envolvendo as variáveis definidas anteriormente.

Conforme discutido na seção anterior, uma economia obedece a dois processos de formação de preço, a precificação dos bens que seguem um valor de referência internacional e um processo de precificação estritamente doméstico. Enquanto para os bens com precificação interna, os custos de produção determinam o preço do bem final, para os bens que seguem um preço de referência internacional, a variável a ser determinada pelos custos de produção são as margens de lucro.

Primeiro, vamos resolver o sistema para taxa de inflação, isto é, realizar a decomposição para os bens que seguem um processo doméstico de precificação como segue:

$$
\begin{aligned}
\pi=(I-A)^{-1} \widehat{\pi} & +(I-A)^{-1} \hat{q}+(I-A)^{-1} \widehat{m l}+(I-A)^{-1} \widehat{r} \\
& +(I-A)^{-1} \hat{t}+(I-A)^{-1} \widehat{m}+(I-A)^{-1} \widehat{s}
\end{aligned}
$$

onde $(\mathbf{I}-\mathbf{A})^{\mathbf{- 1}}$ é a matriz de impacto do modelo de preços de Leontief.

Para ilustrar o significado de cada uma das matrizes e permitir a compreensão do significado da decomposição estrutural e de cada um dos seus elementos, foi montado um

(9) Todos os vetores envolvidos são vetores coluna. 
modelo simplificado 2x2 (dois produtos e duas atividades). A MIP brasileira, que é a base para a construção do modelo I-O de preços, é um modelo 55x55.

$$
\begin{aligned}
& {\left[\begin{array}{l}
\pi_{1} \\
\pi_{2}
\end{array}\right]=(I-A)^{-1}\left[\begin{array}{c}
\widehat{\pi}_{11} a_{11}(0)+ \\
\widehat{\pi}_{12} a_{12}(0)+\widehat{\pi}_{22} a_{22}(0)
\end{array}\right]+(I-A)^{-1}\left[\begin{array}{l}
\hat{q}_{11} a_{11}(0)+\hat{q}_{21} a_{21}(0) \\
\hat{q}_{12} a_{12}(0)+\hat{q}_{22} a_{22}(0)
\end{array}\right]} \\
& +(\mathrm{I}-\mathrm{A})^{-1}\left[\begin{array}{l}
\hat{\mathrm{g}}_{\mathrm{EOB} 1} \mathrm{ml}_{1}(0) \\
\hat{\mathrm{g}}_{\mathrm{EOB} 2} \mathrm{ml}_{2}(0)
\end{array}\right] \\
& +(\mathrm{I}-\mathrm{A})^{-1}\left[\begin{array}{c}
\pi_{\mathrm{MS} 1} \operatorname{cut}_{1}(0)+\hat{\mathrm{q}}_{\mathrm{MS} 1} \operatorname{cut}_{1}(0)+\hat{\mathrm{g}}_{\mathrm{RM} 1} \mathrm{rm}_{1}(0)+\hat{\mathrm{g}}_{\mathrm{OI} 1} \mathrm{oi}_{1}(0) \\
\pi_{\mathrm{MS} 2} \operatorname{cut}_{2}(0)+\hat{\mathrm{q}}_{\mathrm{MS} 2} \mathrm{cut}_{2}(0)+\hat{\mathrm{g}}_{\mathrm{RM} 2} \mathrm{rm}_{2}(0)+\hat{\mathrm{g}}_{\mathrm{OI} 2} \mathrm{Oi}_{2}(0)
\end{array}\right] \\
& +(I-A)^{-1}\left[\begin{array}{l}
\pi_{I P 1} t_{1}(0)+\hat{q}_{I P 1} t_{1}(0) \\
\pi_{I P 2} t_{2}(0)+\hat{q}_{I P 2} t_{2}(0)
\end{array}\right] \\
& +(\mathrm{I}-\mathrm{A})^{-1}\left[\begin{array}{l}
\pi_{\mathrm{m} 1} \mathrm{~m}_{1}(0)+\hat{\mathrm{q}}_{\mathrm{m} 1} \mathrm{~m}_{1}(0) \\
\pi_{\mathrm{m} 2} \mathrm{~m}_{2}(0)+\hat{\mathrm{q}}_{\mathrm{m} 2} \mathrm{~m}_{2}(0)
\end{array}\right] \\
& + \text { (I } \\
& -A)^{-1}\left[\begin{array}{l}
s_{11} a_{11}(0)+s_{21} a_{21}(0)+s_{M S 1} c_{1}(0)+s_{m 1} m_{1}(0)+s_{I P 1} t_{1}(0) \\
s_{12} a_{12}(0)+s_{22} a_{22}(0)+s_{M S 2} c_{1} t_{2}(0)+s_{m 2} m_{2}(0)+s_{I P 2} t_{2}(0)
\end{array}\right]
\end{aligned}
$$

Com:

$$
\begin{gathered}
\mathrm{s}_{11}=\pi_{1} \widehat{\pi}_{11}+\pi_{1} \hat{\mathrm{q}}_{11}+\widehat{\pi}_{11} \hat{\mathrm{q}}_{11}+\pi_{1} \widehat{\pi}_{11} \hat{\mathrm{q}}_{11} \\
\mathrm{~s}_{21}=\pi_{2} \widehat{\pi}_{21}+\pi_{2} \hat{\mathrm{q}}_{21}+\widehat{\pi}_{21} \hat{\mathrm{q}}_{21}+\pi_{2} \widehat{\pi}_{21} \hat{\mathrm{q}}_{21} \\
\mathrm{~s}_{\mathrm{m} 1}=\pi_{\mathrm{m} 1} \hat{\mathrm{q}}_{\mathrm{m} 1} \\
\mathrm{~s}_{\mathrm{IP} 1}=\pi_{\mathrm{IP} 1} \hat{\mathrm{q}}_{\mathrm{IP} 1} \\
\mathrm{~s}_{\mathrm{ms} 1}=\pi_{\mathrm{MS} 1} \hat{\mathrm{q}}_{\mathrm{MS} 1} \\
\mathrm{~s}_{12}=\pi_{1} \widehat{\pi}_{12}+\pi_{1} \hat{\mathrm{q}}_{12}+\widehat{\pi}_{12} \hat{\mathrm{q}}_{12}+\pi_{1} \widehat{\pi}_{12} \hat{\mathrm{q}}_{12} \\
\mathrm{~s}_{22}=\pi_{2} \widehat{\pi}_{22}+\pi_{2} \hat{\mathrm{q}}_{22}+\widehat{\pi}_{22} \hat{\mathrm{q}}_{22}+\pi_{2} \widehat{\pi}_{22} \widehat{\mathrm{q}}_{22} \\
\mathrm{~s}_{\mathrm{m} 2}=\pi_{\mathrm{m} 2} \hat{\mathrm{q}}_{\mathrm{m} 2} \\
\mathrm{~s}_{\mathrm{IP} 2}=\pi_{\mathrm{IP} 2} \hat{\mathrm{q}}_{\mathrm{IP} 2} \\
\mathrm{~s}_{\mathrm{ms} 2}=\pi_{\mathrm{MS} 2} \hat{\mathrm{q}}_{\mathrm{MS} 2}
\end{gathered}
$$

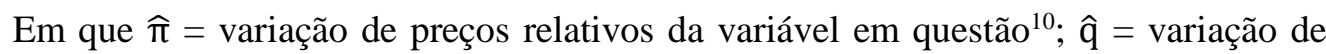
volume relativo da variável em questão; $\hat{\mathrm{g}}=$ crescimento nominal dividido pelo crescimento em volume do VBP; $\mathrm{a}_{\mathrm{ij}}(0)=$ consumo intermediário do produto i pela atividade $\mathrm{j}$ dividido pelo VBP da atividade $\mathrm{j}$ no ano base; $\mathrm{ml}_{\mathrm{j}}(0)=$ margem de lucro da atividade $\mathrm{j}$ no ano base; $\mathrm{cut}_{\mathrm{j}}(0)$ = custo unitário do trabalho na atividade $\mathrm{j}$ no ano base; $\operatorname{rm}_{\mathrm{j}}(0)=$ rendimento misto dividido pelo VBP da atividade $\mathrm{j}$ no ano base; $\mathrm{oi}_{\mathrm{j}}(0)=$ outros impostos livres de subsídios dividido pelo VBP da atividade $\mathrm{j}$ no ano base; $\mathrm{t}_{\mathrm{j}}(0)=$ impostos sobre produtos divididos $\mathrm{VBP}$ da atividade $\mathrm{j}$

(10) Na álgebra matricial é frequente usar o símbolo “"” para fazer referência ao operador de diagonalização de vetores em uma matriz cujos elementos na diagonal principal são os elementos dos vetores originais. O símbolo aqui não guarda nenhuma relação com isso. 
no ano base; $\mathrm{m}_{\mathrm{j}}(0)=$ consumo intermediário importado dividido pelo VBP da atividade $\mathrm{j}$ no ano base.

Com a taxa de inflação de cada atividade, para chegarmos à taxa de inflação de toda a economia basta multiplicarmos cada atividade por sua respectiva participação no VBP e somarmos suas respectivas contribuições. Assim, teremos a contribuição de cada efeito, em cada uma das atividades, para a taxa de inflação da economia (isto é, da taxa de inflação do VBP a preço básico).

É importante tentar interpretar o significado econômico de cada um dos efeitos associados à decomposição da taxa de inflação.

A combinação de insumos usados na produção compõe uma cesta, que pode apresentar evolução em seu preço distinta da evolução do nível geral de preços ou das quantidades necessárias para a produção diferente da evolução da produção total da economia.

O efeito preços relativos está associado ao encarecimento ou barateamento da cesta de insumos usada na produção devido à trajetória do preço (custo) da cesta de insumo distinta da trajetória do preço do VBP (produção total da economia). Se o efeito preço relativo for positivo (negativo), o preço da cesta de insumo cresceu mais (menos) que o preço do VBP, elevando (reduzindo) o coeficiente técnico.

O efeito volume relativo está associado a transformações na cesta de insumo em direção à utilização mais ou menos intensiva do consumo intermediário doméstico por unidade produzida. Isso modifica o valor (custo) da cesta de insumos. Portanto, sempre que aumenta a participação (a preços constantes) do consumo intermediário no produto final, o efeito volume relativo é positivo e o custo de produção sobe, e sempre que se reduz participação dos insumos, o efeito volume relativo é negativo e o custo de produção se reduz.

Mais um elemento a explicar a taxa de inflação é o custo da mão de obra. O efeito CUT pode ser decomposto em duas partes ${ }^{11}$, o crescimento do salário nominal médio (o "preço" da massa salarial), que encarece os custos de produção; e a evolução do requisito unitário de trabalho (o "volume relativo" da massa salarial), que nada mais é do que o inverso do crescimento da produtividade. Assim, quando a produção por trabalhador empregado, a produtividade, cresce (decresce), o requisito unitário de trabalho cai (sobe) e o CUT se reduz (eleva).

O encarecimento dos insumos e o aumento de seu volume relativo também pressionam os custos de produção. $\mathrm{O}$ crescimento nominal das margens de lucro, do rendimento misto e dos demais impostos livres de subsídios dividido pelo crescimento do volume do VBP, ou seja, a expansão nominal por unidade produzida das variáveis nas quais o crescimento não pode ser

(11) O IBGE divulga a massa salarial, assim como o número de trabalhadores empregados por atividade, permitindo o cálculo do salário médio e do nível de emprego por setor. 
desmembrado em variação de preço e de volume ${ }^{12}$ são os últimos elementos com valor econômico da decomposição. Como mencionado, os termos de interação são registrados para obedecer à identidade por trás da decomposição da taxa de inflação, mesmo que não sejam interpretados.

Cabe ressaltar que todos os efeitos associados à decomposição dos bens com preços determinados domesticamente são efeitos sob a ótica de setores verticalmente integrados. Então, por exemplo, o efeito do CUT pode ser desmembrado entre o aumento do salário médio de todos os elos da cadeia produtiva e o efeito produtividade de também todas as etapas do processo produtivo. O efeito CUT mensura a contribuição para a taxa de inflação do encarecimento da mão de obra em todas as fases da produção e não apenas na última etapa.

Como discutido acima, para os bens que seguem um valor de referência internacional, a majoração dos custos de produção explica a evolução das margens de lucro, uma vez que o preço no mercado interno depende do preço internacional e da taxa nominal de câmbio. Assim, ao invés de resolver o sistema para a taxa de inflação, tal como na equação (19), podemos resolver o sistema para as margens de lucro.

$$
\widehat{\mathrm{ml}}=\pi-(A \pi+\widehat{\pi}+\hat{\mathrm{q}}+\hat{\mathrm{r}}+\hat{\mathrm{t}}+\widehat{\mathrm{m}}+\widehat{\mathrm{s}})
$$

Para podermos resolver o sistema para taxa de crescimento das margens de lucro, precisamos pré-multiplicar os dois lados da equação por uma matriz diagonal do tipo:

$$
\mathbf{f}=\left[\begin{array}{cc}
\frac{1}{\mathrm{ml}_{1}(0)} & 0 \\
0 & \frac{1}{\mathrm{ml}_{2}(0)}
\end{array}\right]
$$

A matriz f é usada para que possamos resolver a equação matricial (18) para a variação proporcional das margens de lucro dos setores com preço internacional. Cada célula da diagonal principal deve ser preenchida com a margem de lucro correspondente da atividade no denominador e o valor um no numerador, e todas as demais células devem ser preenchidas com o valor zero.

Resolvendo o sistema para as margens de lucro:

$$
\text { f. } \widehat{m l}=f \cdot \pi-f \cdot(A \pi+\widehat{\pi}+\widehat{q}+\widehat{r}+\hat{t}+\widehat{m}+\widehat{s})
$$

A equação (19) nos permite resolver o sistema para o conjunto da economia (55 atividades). Representando em nosso modelo 2x2:

(12) Para o excedente operacional bruto, o rendimento misto e os outros impostos livres de subsídios, os dados das Contas Nacionais fornecidos pelo Instituto Brasileiro de Geografia e Estatística (IBGE) não apresentam séries a preços do ano corrente e a preço do ano anterior, não permitindo o desmembramento da variação nominal em variação de preço e de volume. 


$$
\begin{aligned}
& {\left[\begin{array}{l}
\hat{\mathrm{g}}_{\text {EOB } 1_{1}} \\
\hat{\mathrm{g}}_{\text {EOB } 1_{2}}
\end{array}\right]=\mathbf{f} \cdot\left[\begin{array}{l}
\pi_{1} \\
\pi_{2}
\end{array}\right]-\mathbf{f} \cdot\left[\begin{array}{ll}
\mathrm{a}_{11}(0) & \mathrm{a}_{21}(0) \\
\mathrm{a}_{12}(0) & \mathrm{a}_{22}(0)
\end{array}\right]\left[\begin{array}{c}
\pi_{1} \\
\pi_{2}
\end{array}\right]-\mathbf{f} \cdot\left[\begin{array}{l}
\widehat{\pi}_{11} \mathrm{a}_{11}(0)+\widehat{\pi}_{21} \mathrm{a}_{21}(0) \\
\widehat{\pi}_{12} \mathrm{a}_{12}(0)+\widehat{\pi}_{22} \mathrm{a}_{22}(0)
\end{array}\right]} \\
& \text {-f. }\left[\begin{array}{l}
\hat{\mathrm{q}}_{11} \mathrm{a}_{11}(0)+\hat{\mathrm{q}}_{21} \mathrm{a}_{21}(0) \\
\hat{\mathrm{q}}_{12} \mathrm{a}_{12}(0)+\hat{\mathrm{q}}_{22} \mathrm{a}_{22}(0)
\end{array}\right] \\
& \text {-f. }\left[\begin{array}{l}
\pi_{\mathrm{MS} 1} \operatorname{cut}_{1}(0)+\hat{\mathrm{q}}_{\mathrm{MS} 1} \operatorname{cut}_{1}(0)+\hat{\mathrm{g}}_{\mathrm{RM} 1} \mathrm{rm}_{1}(0)+\hat{\mathrm{g}}_{\mathrm{OI} 1} \mathrm{Oi}_{1}(0) \\
\pi_{\mathrm{MS} 2} \mathrm{cut}_{2}(0)+\hat{\mathrm{q}}_{\mathrm{MS} 2} \mathrm{cut}_{2}(0)+\hat{\mathrm{g}}_{\mathrm{RM} 2} \mathrm{rm}_{2}(0)+\hat{\mathrm{g}}_{\mathrm{OI} 2} \mathrm{Oi}_{2}(0)
\end{array}\right] \\
& - \text { f. }\left[\begin{array}{l}
\pi_{I P 1} t_{1}(0)+\hat{\mathrm{q}}_{I P 1} \mathrm{t}_{1}(0) \\
\pi_{\mathrm{IP} 2} \mathrm{t}_{2}(0)+\hat{\mathrm{q}}_{\mathrm{IP} 2} \mathrm{t}_{2}(0)
\end{array}\right]-\mathbf{f} \cdot\left[\begin{array}{c}
\pi_{\mathrm{m} 1} \mathrm{~m}_{1}(0)+\hat{\mathrm{q}}_{\mathrm{m} 1} \mathrm{~m}_{1}(0) \\
\pi_{\mathrm{m} 2} \mathrm{~m}_{2}(0)+\hat{\mathrm{q}}_{\mathrm{m} 2} \mathrm{~m}_{2}(0)
\end{array}\right] \\
& \text {-f. }\left[\begin{array}{l}
s_{11} a_{11}(0)+s_{21} a_{21}(0)+s_{M S 1} c_{1} t_{1}(0)+s_{m 1} m_{1}(0)+s_{I P 1} t_{1}(0) \\
s_{12} a_{12}(0)+s_{22} a_{22}(0)+s_{M S 2} c_{1} t_{2}(0)+s_{m 2} m_{2}(0)+s_{I P 2} t_{2}(0)
\end{array}\right]
\end{aligned}
$$

A evolução das margens de lucro depende da taxa de crescimento do preço do bem no mercado internacional e da variação da taxa nominal de câmbio, que determinam a inflação em moeda local, e do crescimento de todas as variáveis de custo. A decomposição como proposta na equação (19) não trabalha com setores verticalmente integrados por dois motivos. $O$ primeiro é a própria solução do sistema para as margens de lucro que não produz um resultado como o da decomposição da taxa de inflação, e o segundo é o fato da análise ser realizada para os bens com preço internacional. Como o objetivo é avaliar o comportamento das margens de lucro, trabalhar com os setores verticalmente integrados não é o mais interessante. Por exemplo, vamos supor que o custo unitário do trabalho crescesse na produção dos bens com preço internacional que são utilizados como insumo na "última rodada" da produção de determinado bem final com preço internacional. Os insumos também apresentam preço internacional, como o próprio bem final, assim, o mais importante é observar o encarecimento do consumo intermediário para a "última rodada" do processo produtivo. Trabalhando com setores verticalmente integrados, o aumento do custo unitário do trabalho nas fases anteriores do processo produtivo se misturaria com o aumento do mesmo na última etapa. Não analisaríamos, assim, a evolução das margens de forma adequada. Enquanto para os bens com preço doméstico, o mais interessante é analisar o comportamento da taxa de inflação pensando em setores verticalmente integrados, para analisar a evolução das margens de lucro dos bens com preço internacional é mais interessante observar o que ocorre nos custos na última etapa da cadeia produtiva. Assim, podemos separar tudo que aconteceu nas etapas anteriores, dentro do efeito chamado consumo intermediário, de tudo que aconteceu na última etapa. Todos os efeitos que já estavam presentes na decomposição estrutural dos bens com preço doméstico se mantêm presentes agora, porém, sua influência está restrita ao efeito direto, e não mais os efeitos direto e indireto combinados. Como dito, o efeito indireto estará todo dentro do encarecimento do consumo intermediário.

\section{A separação dos bens em preço doméstico e preço internacional}

Para analisar a dinâmica inflacionária brasileira é preciso separar as atividades de acordo com as características comuns de formação de preço. Para isso, optou-se por trabalhar com duas classificações: bens que seguem um valor de referência internacional (e.P*), e bens 
com precificação doméstica, no qual o preço no mercado interno não guarda relação com o preço $^{13}$ internacional, dependendo das variáveis de custo, como nas equações (5) e (8).

Para implementar as classificações, primeiro foram coletados os dados de exportações mundiais e brasileiras disponíveis na plataforma do Banco Mundial - Comtrade (WITS World Integrated Trade Solution $)^{14}$ de 1989 até 2013. Para viabilizar a leitura dos dados e sua subsequente análise mediante a estrutura do Sistema de Contas Nacionais (SCN), os dados extraídos com a classificação de seis dígitos (HS6) foram agregados utilizando um tradutor HS6xSCN disponibilizado pelo Grupo de Indústria e Competitividade (GIC/UFRJ). A agregação reduziu o número de produtos de mais de 5000 a partir da classificação HS6 para 85 produtos $^{15} \mathrm{SCN}$.

Os dados são apresentados em valor e por peso $(\mathrm{Kg})$, permitindo o cálculo do preço por Kg. Para poder avaliar a evolução do preço dos produtos foram montados índices de preço do tipo Laspeyres. Cada um dos 85 produtos SCN constituiu uma cesta de bens, com a participação sendo definida pela parcela dos produtos HS6 no produto resultante da agregação, ou seja, sua respectiva cesta. A título de ilustração, vamos supor o seguinte exemplo. Três produtos (produtos 1, 2 e 3) na classificação HS6 são agregados através do tradutor para o produto A do SCN. O peso dos produtos 1, 2 e 3, em valor, são respectivamente $25 \%, 35 \%$ e $40 \%$ do produto A no ano base (Índice de Laspeyres). A partir disso, é possível montar a evolução de preço do produto A, mediante a participação dos produtos 1, 2 e 3 no ano base (1989) e a evolução dos preços observada para esses produtos ao longo de todo o período analisado. O objetivo de trabalhar com um período de tempo mais extenso do que o utilizado no trabalho foi observar a presença ou ausência de uma tendência de longo prazo para o preço das exportações brasileiras vis-à-vis as exportações mundiais ${ }^{16}$.

Assim, foram construídas duas séries com 85 índices de preço cada, uma para as exportações mundiais e outra para as exportações brasileiras de 1989 até 2013. Com os índices de preços disponíveis foram calculadas as taxas de crescimento do nível de preço para cada um dos produtos de 1990 a 2013. As quatro maiores dispersões encontradas para as taxas de crescimento foram substituídas pela média de crescimento do produto para todo o período, ou seja, os outliers foram substituídos através da interpolação.

(13) Ou sequer existe algum produto no mercado internacional que possa ser considerado análogo ao do mercado doméstico, como, por exemplo, acontece para alguns serviços.

(14) Disponível em https://wits.worldbank.org/. Acesso em: 10 jan. 2015.

(15) Apesar do SCN possuir 110 produtos, apenas 85 deles apresentaram comércio internacional segundo dos dados do Comtrade.

(16) Nos dados das exportações brasileiras, para alguns produtos SCN 110, a participação de 1989 era nula e positiva posteriormente. Nesses casos, foi usada a participação do ano de 2013. Além disso, alguns produtos não apresentavam registro na classificação HS6 (campo vazio) para os primeiros anos da série e depois para alguns anos isolados, resultando em produto SCN com valor zero. Para resolver esse problema a série foi interpolada. O primeiro dado positivo subsequente foi dividido pela média de crescimento de todo o período para o produto em questão. 
Em seguida, os 85 produtos foram analisados graficamente comparando a evolução da série de preços com classificação SCN das exportações mundiais com a mesma série para as exportações brasileiras no período 1990-2013 e identificados 25 produtos com preços internacionais e 60 produtos com preço doméstico.

A decomposição estrutural da taxa de inflação trabalha com a análise dos setores (atividades) e não com base na classificação por produto. Assim, a análise da formação de preço em termos dos 110 produtos das Contas Nacionais, precisou ser aplicada a classificação por setor de atividade, que são 55 no total. Para poder fazer isso, foi calculada a participação de cada produto no total produzido (VBP) da atividade para os anos de 2000 a 2009 e contabilizada a média. Desse modo, foi possível visualizar quais setores de atividades eram compostos por produtos com característica de precificação internacional e quais se caracterizavam por precificação doméstica. Todas as atividades em que mais de $40 \%$ da produção estava concentrada em produtos que seguiam o respectivo preço de referência internacional foram classificadas como setores com preço internacional e os demais como setores com preço doméstico. Isto é, todas as atividades em que os 25 produtos nos quais os índices de preço indicavam o acompanhamento de um preço de referência internacional representavam mais de $40 \%$ do VBP, foram classificadas como atividades com preço mundial, atividades em que seu processo de precificação está associado ao acompanhamento de um valor mundial de referência. As atividades em que a participação do VBP dos 25 produtos com precificação internacional representava menos de $40 \%^{17}$ do VBP, foram classificados como precificação doméstica ${ }^{18}$.

Dos 55 setores de atividade das Contas Nacionais, seis foram classificados como setores com preço internacional, a saber: "Minério de ferro", "Alimento e Bebidas", "Álcool”, "Fabricação de resinas e elastômeros", "Produtos e preparos químicos diversos" e "Fabricação de aço e derivados"19.

Antes de discutirmos os resultados da decomposição, é necessário fazer uma qualificação. Os valores disponibilizados pelo IBGE e atualizados por Neves (2013) são apresentados sempre, tanto para preços correntes como para preços do ano anterior, com base no conceito de preço médio anual. Portanto, estudando o período 2000-2009, não é possível

(17) Das atividades classificadas como preço internacional, "Alimentos e Bebidas" foi a que apresentou a participação mais baixa, com 49\% do VBP constituído de produtos com preço internacional, todas as demais tiveram de $86 \%$ para cima.

(18) Foi utilizada, ainda, uma terceira classificação, aplicada para os serviços prestados pelo setor público ("Educação Pública" "Saúde Pública" e "Administração Pública e Seguridade Social”). Esse grupo apresenta a característica do bem (serviço) não ser adquirido pelos consumidores (prestado aos cidadãos) mediante pagamento, ou seja, não apresentam preço monetário. Assim, foram retirados da análise da dinâmica inflacionaria brasileira. Todas as operações necessárias para a decomposição estrutural foram realizadas com os 55 setores de atividade (matriz quadrada), porém, posteriormente, foram retiradas essas três atividades. O total da economia (agregado) foi calculado considerando a soma dos dois primeiros grupos como $100 \%$ da economia brasileira.

(19) A atividade "Petróleo e Gás Natural" foi classificada como setor com precificação interna, uma vez que a política de preços adotada fez com que o principal produto da atividade, também chamado de "petróleo e gás natural", e que responde por 99\% do VBP do setor, não apresentasse trajetória compatível com os preços internacionais. 
calcular o índice de preço para o ano 2000. Essa é uma diferença importante em relação à metodologia utilizada pelo IBGE para o cálculo do IPCA (Índice de Preço ao Consumidor Amplo). No cálculo do IPCA, é observado o preço de um bem em determinado dia de cada mês, sendo, portanto, possível calcular índices de preços mensais e, posteriormente, anuais. Usando a métrica do preço médio são necessários dois anos para poder calcular o índice de preço. De modo geral, em uma série com n anos, é possível calcular n-1 índices de preço. Com base na metodologia desenvolvida para a execução da decomposição estrutural da taxa de inflação, devemos usar os coeficientes técnicos do ano base na montagem da MIP e as taxas de crescimento do volume e do nível de preços partindo, evidentemente, do ano base.

Mais uma consequência da metodologia da decomposição estrutural é a importância de dividir adequadamente o período de análise em fases que apresentem características comuns. Vamos supor que no ano 1 os salários dobrem, e no ano 2 eles se reduzam à metade, voltando ao patamar do ano 0. Pela execução da decomposição, se comparássemos o valor médio do ano 2 com o valor médio do ano 0 , iríamos decompor uma variação nula, mesmo os salários tendo exercido importante contribuição para a majoração de custos e preços no ano 1 e para a redução no ano 2. Nesse exemplo, seria necessário fazer a decomposição para os dois subperíodos separados para poder captar a pressão altista no primeiro ano e deflacionista no segundo. Portanto, para aproveitar o máximo possível de informação que a decomposição estrutural da taxa de inflação é capaz de fornecer, é importante dividir o período de análise em fases que apresentem trajetórias comuns para as variáveis chaves do sistema de preço.

\section{0 processo inflacionário brasileiro de 2001 a 2009}

Os anos 2000 foram marcados por um período de estagnação (2001-2003), por uma fase de aceleração do crescimento (2004-2008), aproveitando o cenário internacional favorável, tanto em termos de liquidez como em termos da taxa de crescimento da economia mundial e do comércio internacional, e por um ano de contração (2009), fruto do momento mais acentuado da crise do Subprime. De modo geral, essa década foi marcada pela maior taxa de crescimento desde a década de 1970, pela queda da taxa de desemprego e de uma expansão da rede de proteção social que permitiram uma redução relevante da pobreza e da indigência (pobreza extrema) e da desigualdade de renda.

O Gráfico 1 mostra que a taxa de inflação ao longo dos anos 2000. Podemos observar que a taxa mais elevada ocorreu em 2003, fruto do efeito da desvalorização cambial e do começo do super ciclo das commodities no mercado internacional. A inflação dos bens com preço doméstico também foi crescente até 2003 e depois passou a cair. Notamos que ela se reduziu menos do que a inflação dos bens com preço internacional. A inflação brasileira acompanhou mais de perto a taxa de inflação dos bens com preço doméstico e tem clara desaceleração, como evidencia a linha de tendência.

A menor taxa de inflação da economia brasileira aconteceu em 2006. O ano de 2008 marca um aumento relevante da taxa de inflação, que foi mais forte para os bens que seguem 
um valor mundial de referência, enquanto, o ano de 2009 marca uma forte desaceleração, também mais forte para os bens com preço internacional.

Gráfico 1

Taxas de inflação no período 2000-2009

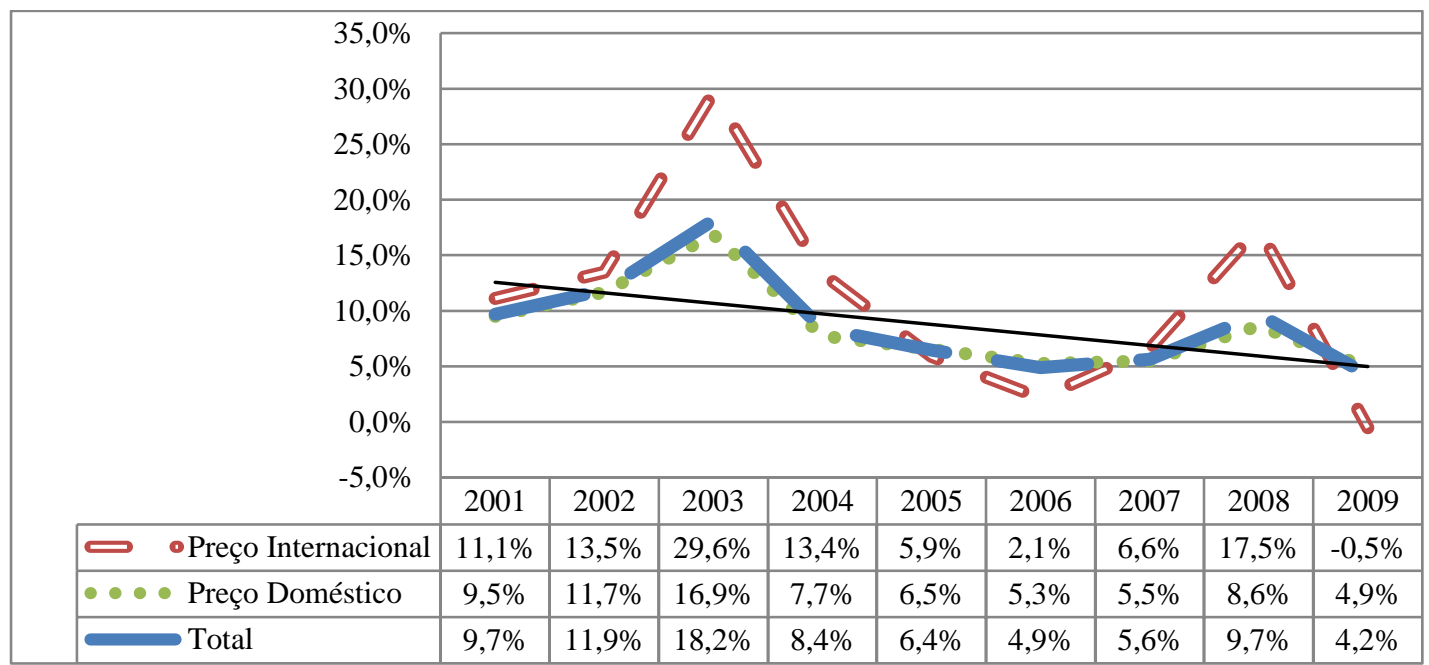

Fonte: SCN/IBGE e Neves (2013). Elaboração própria.

A análise do período 2001-2009 foi dividida em três fases seguindo a narrativa sobre o processo inflacionário brasileiro sob a ótica da inflação de custos da Abordagem do Excedente, chamado de cost push inflation. Seguindo Bastos e Braga (2010), Braga (2011), Summa e Braga (2013), Braga (2013) e Summa (2014), podemos dividir o período 2001-2009 em três fases ${ }^{20}$. No subperíodo 2001-2003, a taxa nominal de câmbio se desvalorizou enquanto o preço das commodities caiu em Dólar em 2001 e 2002, e cresceu em 2003. O salário nominal cresceu abaixo da produtividade do trabalho e o salário real caiu. A partir de 2004, o câmbio nominal (média anual) iniciou um forte movimento de valorização, junto ao acelerado crescimento do preço das commodities em moeda estrangeira. Também a partir de 2004, o salário real começou a crescer. Adicionalmente, o padrão de crescimento da economia brasileira começou a se modificar, quando comparado ao triênio anterior. A partir de 2006, o salário nominal passou a crescer mais rápido, fazendo com que o custo unitário do trabalho passasse a explicar parcela maior da dinâmica inflacionária. Foi o começo de certa inflação salarial na economia brasileira. Na fase 2006-2009, a dinâmica cambial foi mais irregular, principalmente pelo impacto que a crise internacional exerceu sobre a economia mundial e brasileira no último trimestre de 2008. Nesse trimestre, a taxa nominal de câmbio se desvalorizou rapidamente, e o preço internacional das commodities caiu rápido. Já em 2009, as

(20) Para uma discussão do processo inflacionário brasileiro em outra perspectiva, ver Modenesi et al. (2016), Saraiva e Paula (2015), Modenesi (2014) e Modenesi e Araújo (2012). 
duas variáveis voltam a exibir o comportamento imediatamente anterior à queda do banco americano Lehman Brothers, porém, a mudança de patamar no fim de 2008 afetou as cotações médias de 2009. A taxa nominal média de câmbio de 2009 foi superior à taxa de 2008, e o preço das commodities, inferior. Do início do subperíodo até seu final, referência para a realização da decomposição estrutural, o câmbio se valorizou e o preço das commodities aumentou, em Dólar. Portanto, na terceira fase, o câmbio nominal manteve sua trajetória, assim como o preço das commodities. A variável que passou a ter novo comportamento foi o custo unitário do trabalho, que apresentou maior crescimento. Somado a isso, o ano de 2006 marca uma moderada inflexão na política econômica, pois a política fiscal passou a ser um pouco mais expansiva e o setor público passou a se preocupar explicitamente em elevar o investimento público (Serrano; Summa, 2011).

A decomposição apresenta resultados acumulados para os subperíodos escolhidos, ou seja, a taxa de inflação acumulada de 2001 a 2003, de 2004 a 2005, e de 2006 a 2009. Como os três períodos possuem extensões distintas, com o objetivo de tornar os resultados da decomposição comparáveis e mais facilmente analisáveis, a partir da taxa acumulada para cada subperíodo, foi calculada a taxa média (geométrica) para cada uma das três fases. Portanto, todos os resultados apresentados para a decomposição se referem à contribuição média (anual) a taxa de inflação.

Tabela 1

Variáveis selecionadas 2000-2009

\begin{tabular}{l|c|c|c}
\hline & $\begin{array}{c}\text { Bens com Preço } \\
\text { Internacional }\end{array}$ & $\begin{array}{c}\text { Bens com Preço } \\
\text { Doméstico }\end{array}$ & Total \\
\hline Participação no VBP (ano base 2000) & $10,5 \%$ & $89,5 \%$ & $100,0 \%$ \\
\hline Taxa de inflação média anual 2001-2003 & $18,1 \%$ & $12,7 \%$ & $13,3 \%$ \\
\hline Contribuição média à taxa de inflação (p.p.) 2001-2003 & 1,90 & 11,36 & 13,27 \\
\hline Participação no VBP (ano base 2003) & $11,6 \%$ & $88,4 \%$ & $100,0 \%$ \\
\hline Taxa de inflação média anual 2004-2005 & $9,9 \%$ & $7,1 \%$ & $7,4 \%$ \\
\hline Contribuição média à taxa de inflação (p.p.) 2004-2005 & 1,15 & 6,25 & 7,40 \\
\hline Participação no VBP (ano base 2005) & $10,7 \%$ & $89,3 \%$ & $100,0 \%$ \\
\hline Taxa de inflação média anual 2006-2009 & $6,9 \%$ & $5,9 \%$ & $6,0 \%$ \\
\hline Contribuição média à taxa de inflação (p.p.) 2006-2009 & 0,73 & 5,27 & 6,00 \\
\hline
\end{tabular}

Fonte: SCN/IBGE e Neves (2013). Elaboração própria.

No primeiro subperíodo, a taxa (média) de inflação alcançou 13,27\% ao ano (a.a.), no segundo subperíodo caiu para 7,4\% a.a. e, no terceiro, para $6 \%$ ao ano, menos da metade do observado para o primeiro triênio. Mais uma constatação é que a contribuição dos bens com preço doméstico é sempre muito maior do que a contribuição dos bens que seguem um valor mundial de referência, devido à participação também muito maior da categoria na economia 
brasileira (medida a partir do VBP). A terceira constatação é que a taxa de inflação dos bens com preço internacional foi superior nos três subperíodos, e que a diferença foi sendo reduzida ao longo dos anos. Portanto, a contribuição dos bens com preço doméstico só foi maior devido a sua participação no VBP, uma vez que a taxa de crescimento da outra categoria foi superior.

Em 2001-2003, a inflação dos bens com preço internacional foi de $18,1 \%$ ao ano e promoveu uma contribuição (média) para a inflação (total) da economia brasileira de 1,9 pontos percentuais (p.p.) ao ano, enquanto a inflação dos bens com preço interno foi de $12,7 \%$ a.a. e promoveu uma contribuição (anual) de 11,36 p.p. para a taxa de inflação, que foi de $13,27 \%$ (a.a.).

Durante o primeiro triênio, o preço das commodities caiu em 2001 e 2002, e passou a subir em 2003. Comparando 2003 com 2000, referência para a decomposição estrutural, o preço das commodities caiu no primeiro subperíodo. Nessa mesma época, a taxa nominal de câmbio passou por uma desvalorização média de $19 \%$ ao ano, ou seja, a inflação dos bens com preço externo (e.P*) se deu basicamente pela desvalorização cambial. No segundo subperíodo, o preço das commodities já apresentou tendência oposta, com elevado crescimento enquanto o câmbio também inverteu a sua trajetória e passou a se valorizar. Nos anos 2004-2005, a redução da inflação dos bens com preço mundial só foi possível graças à valorização cambial, uma vez que a cotação internacional subiu. No último quadriênio, a despeito da oscilação da trajetória ao longo dos quatro anos, houve valorização da taxa de câmbio, embora mais amena, e crescimento, também mais ameno, da cotação internacional. A inflação da categoria continuou a cair. Comparando com o primeiro triênio, podemos repetir a constatação, uma vez que os preços internacionais subiram, só foi possível reduzir a taxa de inflação devido à valorização cambial. A taxa de inflação de 6,9\% corresponde a aproximadamente dois quintas da taxa de 18,1\% observada para 2001-2003. Comparando com 2004-2005, a redução foi possível por uma combinação mais suave entre crescimento da cotação mundial e valorização cambial.

Compreendidos os fatores que explicam a trajetória dos bens com preço internacional, podemos analisar os determinantes para a taxa de inflação dos bens que possuem um processo estritamente doméstico de formação de preço. Essa segunda categoria, que representa uma parcela bem maior da economia, medida pela participação no VBP, também apresentou taxas de inflação declinantes ao longo dos anos. A taxa de inflação dos bens com preço formado no mercado interno se reduziu de $12,7 \%$ a.a. no primeiro triênio, para 7,1\% a.a. em 2004-2005 e $5,9 \%$ a.a. no último quadriênio. Embora tenha sido uma queda menos intensa, a tendência geral de redução substancial da taxa de inflação a cada subperíodo foi mantida. 
Tabela 2

Contribuição dos bens com preço doméstico para a taxa de inflação

\begin{tabular}{l|c|c|c}
\hline & $2001-2003$ & $2004-2005$ & $2006-2009$ \\
\hline Insumos domésticos - Efeito preços relativos & 0,48 & 0,51 & 0,15 \\
\hline Insumos domésticos - Efeito volume relativo & $-0,29$ & $-0,56$ & $-0,01$ \\
\hline Insumos importados - Efeito volume relativo & $-0,08$ & 0,30 & 0,39 \\
\hline Insumos importados - Efeito preço & 1,77 & 0,15 & 0,05 \\
\hline Impostos sobre produtos - Efeito volume relativo & 0,10 & $-0,04$ & $-0,04$ \\
\hline Impostos sobre produtos - Efeito preço & 0,74 & 0,46 & 0,24 \\
\hline Outros Impostos e Subsídios & 0,23 & 0,16 & 0,15 \\
\hline Subtotal de Impostos & 1,06 & 0,59 & 0,36 \\
\hline Salário médio & 2,58 & 2,48 & 3,09 \\
\hline Produtividade do Trabalho & 0,47 & 0,05 & $-0,25$ \\
\hline Custo Unitário do Trabalho (nominal) & 3,05 & 2,53 & 2,85 \\
\hline Margens de lucro (nominais) & 4,66 & 2,88 & 1,55 \\
\hline Rendimento Misto & 0,94 & 0,16 & 0,23 \\
\hline Termos de interação & $-0,22$ & $-0,29$ & $-0,31$ \\
\hline Total & 11,36 & 6,25 & 5,27 \\
\hline
\end{tabular}

Fonte: SCN/IBGE e Neves (2013). Elaboração própria.

A decomposição estrutural da taxa de inflação fornece uma descrição exaustiva (completa) dos elementos responsáveis pela majoração dos preços. Enquanto para os bens com preço internacional, a evolução depende da taxa nominal de câmbio e do preço de referência internacional, para os bens com preço interno, a taxa de inflação depende de todos os efeitos expostos na Tabela 2. Como a decomposição é realizada para explicar o impacto de cada efeito sobre a dinâmica inflacionária, a dimensão dos efeitos está associada à participação de cada categoria no VBP da economia.

Na Tabela 2, podemos observar a influência de cada um dos efeitos associados à decomposição estrutural sobre a taxa de inflação total da economia. Olhando para o primeiro subperíodo, da contribuição de 11,36 p.p. dos bens com preço interno, 0,48 p.p. corresponde ao efeito preços relativos, 0,29 p.p. à contribuição negativa (deflacionista) do efeito volume relativo do consumo intermediário doméstico, 0,08 p.p. à contribuição negativa do efeito volume relativo do consumo intermediário importado, e assim por diante. A soma de todos os efeitos corresponde, evidentemente, à própria contribuição desta categoria para a taxa de inflação brasileira, 11,36 pontos percentuais.

A decomposição da taxa de inflação nos permite observar que o encarecimento do consumo intermediário importado promoveu uma contribuição de 1,77 p.p. ao ano. O preço dos insumos importados depende da taxa nominal de câmbio e dos preços internacionais, assim como os bens finais com preço de referência internacional. Vale lembrar que estamos 
analisando o impacto de cada um dos efeitos em termos de setores verticalmente integrados, portanto, o encarecimento dos insumos intermediários importados em questão não se refere apenas ao encarecimento dos insumos na etapa imediatamente anterior da produção, mas sim em todas as etapas do processo produtivo. A contribuição de 1,77 p.p. é a contribuição acumulada da desvalorização cambial somada à mudança na cotação internacional dos insumos sobre os setores com preço doméstico desde a primeira etapa do processo produtivo até a última.

Se quisermos analisar a influência sobre toda a economia brasileira do efeito combinado da variação da taxa de câmbio nominal com a variação da cotação internacional dos insumos e bens finais, devemos somar a contribuição de 1,77 p.p. com a de 1,90 p.p., resultando em uma contribuição de 3,67 pontos percentuais. Essa contribuição (média) de 3,67 p.p. corresponde a $27,7 \%$ de toda a inflação (média) do período, reforçando a proposição de Braga (2013) de que a trajetória do câmbio nominal somada à dinâmica das commodities no mercado internacional é uma variável chave para explicar o processo inflacionário brasileiro ${ }^{21}$.

A evolução do volume relativo de impostos sobre produtos também influencia a trajetória dos preços. No triênio 2001-2003, notamos que esse fenômeno produziu um impacto de 0,10 ponto percentual, em média, sobre o índice de inflação brasileiro. Uma influência que pode ser considerada pequena. Já a evolução do "preço" do imposto, ou seja, o aumento do nível de preço da base de incidência dos impostos elevou o nível de preços, em média, em 0,74 pontos percentuais.

Os aumentos do rendimento misto e dos outros impostos livres de subsídios por unidade produzida contribuíram com 0,94 e 0,23 p.p. respectivamente. O total promovido pela tributação consiste, então, nos efeitos preço e volume relativo dos impostos sobre produtos e no aumento dos demais impostos livres de subsídios por unidade produzida. A tributação, assim, contribuiu, na média, com 1,06 p.p. ao ano para o processo inflacionário de 2001 a 2003.

Os efeitos que faltam ser analisados são os efeitos associados ao EOB e a massa salarial (acrescida das contribuições sociais sobre a folha de pagamento). Como já discutido, o IBGE disponibiliza tanto a massa salarial, quanto o número de trabalhadores empregados, por atividade. Assim, é possível separar a evolução do custo da massa salarial por unidade produzida em efeito salário nominal médio (ou custo salarial médio) e efeito volume relativo (ou efeito produtividade do trabalho). Os dois combinados nos dizem a influência que o crescimento da folha salarial por unidade produzida, isto é, do custo unitário do trabalho (CUT), exerceu sobre a dinâmica inflacionaria. Para o EOB, não é possível fazer essa separação, temos apenas o efeito da expansão do EOB (em valor) por unidade produzida. Isto nada mais é do que a tentativa de recompor a margem de lucro por parte do rendimento do

(21) Como o reajuste de preço dos bens monitorados era bastante sensível à taxa nominal de câmbio na primeira metade da década, devido a vinculação à índices preços sensíveis a variação cambial, a influência da desvalorização cambial possivelmente foi maior do que a mensurada por esses dois efeitos da decomposição estrutural. Para uma discussão sobre os efeitos da mudança nas regras de reajuste dos bens monitorados, ver Braga (2011, 2013) e Martinez e Cerqueira (2013). 
capital com base em alguma meta de rentabilidade a ser alcançada, que pode ser frustrada ou bem-sucedida. Portanto, o efeito margens de lucro consiste no impacto sobre a dinâmica inflacionária da tentativa do capital de atingir determinada rentabilidade.

Nos anos 2001-2003, o efeito salário nominal médio contribuiu com 2,58 p.p. (a.a.) para a taxa de inflação brasileira, e como a produtividade do trabalho caiu no Brasil nesse triênio, o efeito produtividade foi positivo, isto é, pressionou os custos de produção, promovendo uma contribuição de 0,47 p.p. ao ano. O efeito margens de lucro contribuiu com 4,66 p.p. ao ano para a taxa de inflação.

Notamos que as margens de lucro se configuraram como o principal elemento causador da majoração de preços. O segundo efeito a mais pressionar os preços foi o CUT, enquanto o terceiro foi o efeito preço do consumo intermediário importado. Vale lembrar que o encarecimento dos produtos finais dos bens com preço internacional também foi importante para explicar a taxa de inflação (média) do período. Assim, podemos concluir que a expansão do salário nominal médio (e a queda na produtividade do trabalho), a desvalorização cambial e a evolução das margens de lucro foram os principais responsáveis pela dinâmica inflacionária no triênio 2001-2003.

Analisando o biênio 2004-2005, observamos que a taxa de inflação caiu significativamente para 7,4\% a.a., fruto de uma contribuição de 1,15 p.p. dos bens com preço internacional e de 6,25 p.p. dos bens com preço doméstico.

O efeito preços relativos contribuiu com 0,51 p.p. e o efeito volume relativo do consumo intermediário importado com 0,30 p.p., enquanto o efeito volume relativo do insumo intermediário doméstico promoveu uma contribuição deflacionista de 0,56 p.p. ao ano. Adicionalmente, os três efeitos associados à tributação, juntos, contribuíram com 0,59 p.p. para a taxa de inflação brasileira.

Percebemos também que a contribuição do encarecimento (efeito preço) do insumo intermediário importado caiu sensivelmente para apenas 0,15 p.p., valor bem inferior ao do período anterior. Esse resultado se deve à valorização cambial, uma vez que a cotação internacional passou a subir a taxas elevadas. Somando o efeito preço do consumo intermediário importado com a contribuição dos bens com preço internacional, chegamos à contribuição combinada da trajetória do câmbio e da cotação internacional de 1,3 p.p., também bem inferior a observada antes (de 3,67 p.p.) ${ }^{22}$. A valorização cambial, portanto, foi capaz de compensar o grande crescimento dos preços internacionais em moeda estrangeira e auxiliou a reduzir a taxa de inflação no Brasil.

A evolução do CUT continuou pressionando os preços. A taxa média de crescimento do salário nominal (junto das contribuições patronais) foi similar ao observado no triênio anterior. A contribuição à mudança de preço foi menor, devido à queda de participação do CUT

(22) Essa diferença corresponde a mais de dois quintos de toda a desaceleração da taxa média de inflação entre 20012003 e 2004-2005. 
no VBP e a queda menos intensa da produtividade do trabalho. Apesar da queda da contribuição do CUT de 3,05 p.p. para 2,53 p.p. ao ano, a queda mais acentuada da taxa de inflação fez com que o CUT explicasse uma parcela maior da taxa de inflação brasileira nos anos 2004-2005. A inflação salarial passou a ser mais importante para explicar a dinâmica de preços na economia brasileira ${ }^{23}$.

O impacto das margens também se reduziu. A contribuição caiu de 4,66 p.p. para 2,88 p.p. no segundo subperíodo. Já a importância relativa das margens subiu ligeiramente ${ }^{24}$. Mesmo tendo permanecido maior, a tentativa de (ao menos) recomposição do rendimento do capital pressionou o nível de preço em magnitude mais próxima a pressão exercida pela tentativa de ampliação do rendimento da força de trabalho. A pressão exercida por essas variáveis distributivas se aproximou. Por fim, o crescimento do rendimento misto por unidade produzida pressionou os preços em 0,16 p.p. ao ano, sensivelmente menos do que no triênio anterior $(0,94$ p.p.).

No quadriênio final de nossa análise, a taxa de inflação dos bens com preço internacional se reduziu a cerca de dois quintos da observada nos anos 2001-2003, enquanto a dos bens com preços domésticos se reduziu para um pouco menos da metade.

Nesse período, podemos observar que o efeito volume relativo dos insumos importados foi mais elevado (0,39 p.p.) e respondeu por parcela maior da taxa de inflação. O efeito preços relativos contribuiu com 0,15 p.p. ao ano, e o efeito volume relativo do consumo intermediário doméstico foi praticamente nulo. Os três primeiros efeitos presentes na Tabela 2 tem natureza bastante distinta e é difícil agrupá-los através de algum elemento comum. A única coisa que pode ser dita é os três estão associados à mudança nos coeficientes técnicos de produção. Em 2001-2003, esses três efeitos juntos foram responsáveis por $0,8 \%$ da inflação no Brasil, ou 0,11 p.p. ao ano. Em 2004-2005, responderam por 3,3\% de toda a taxa de inflação, ou 0,24 p.p. ao ano. E em 2006-2009, responderam por 8,8\% da dinâmica de preços, com uma contribuição de 0,53 p.p. ao ano. Assim, se agruparmos esses três efeitos, mesmo sendo de natureza tão distinta, notamos que a mudança dos coeficientes técnicos passou a pressionar mais intensamente os custos de produção ao longo da década.

A tributação contribuiu com 0,36 p.p. ao ano para a taxa de inflação brasileira e foi a variável a apresentar maior estabilidade ao longo de todo o período. Apesar de seus três efeitos variarem um pouco mais ao longo das fases, a importância relativa do total associado à tributação pouco oscilou, se diferenciando de todos os demais elementos.

Dando sequência a um processo iniciado na fase anterior, o efeito preço do consumo intermediário importado continuou caindo e alcançou a menor contribuição de todo o período, apenas 0,05 p.p. ao ano. O efeito combinado de taxa de câmbio e preço internacional somou

(23) Enquanto nos anos 2001-2003, o efeito salário médio somado ao efeito produtividade explicaram 23\% da inflação total de $13,27 \%$ ao ano, em 2004-2005, esses efeitos combinados passaram a explicar 34,2\% da inflação de 7,4\% ao ano.

(24) De 35,1\% em 2001-2003 para 38,9\% em 2004-2005. 
0,79 p.p. ao ano, não apenas o menor das três fases como também representou o menor percentual da taxa de inflação. Neste quadriênio, o efeito preço dos insumos importados e a variação de preço dos bens finais com preço internacional, juntos, respondem por um pouco mais de um oitavo de toda a inflação brasileira. Na fase de desvalorização cambial (20012003), esses efeitos somados respondiam por mais de um quarto do total ${ }^{25}$. Mesmo com a reversão da trajetória do preço das commodities comparativamente ao início da década, o preço em Real desses bens cresceu a taxas menores, reforçando a importância da valorização cambial como um instrumento central na contenção da inflação brasileira.

O efeito associado ao crescimento do salário médio alcançou sua maior contribuição para todo o período, 3,09 p.p. ao ano. Um resultado novo para a série 2006-2009, é que finalmente a produtividade apresentou crescimento positivo, contendo a ascensão do custo unitário trabalho. O efeito produtividade contribuiu para a inflação ser 0,25 p.p. menor. Esse resultado é especialmente importante, pois fez o efeito CUT ser menor do que o observado em 2001-2003. Mesmo com um crescimento mais elevado do salário nominal médio, a evolução favorável da produtividade do trabalho amenizou a pressão sobre os custos de produção. Como a taxa de inflação continuou caindo, a importância relativa desse efeito subiu novamente ${ }^{26}$.

Como contraponto, a pressão exercida pelo aumento das margens de lucro foi o menor da série, com uma contribuição média de 1,55 p.p. ao ano. Mesmo olhando para a importância relativa $^{27}$, a relevância do efeito margens de lucro se reduziu ao longo da década ${ }^{28}$.

Portanto, durante o quadriênio 2006-2009, a queda da taxa de inflação esteve associada à manutenção da valorização nominal da taxa de câmbio e à redução do efeito associado às margens de lucro. A pressão exercida pelo CUT aumentou e passou a explicar uma parcela maior da dinâmica inflacionária.

Associada à mudança de comportamento das variáveis distributivas e, assim, dos efeitos a comandar o comportamento da taxa de inflação, notamos também, uma mudança de composição nos setores que apresentaram as dez maiores contribuições para a taxa de inflação brasileira.

Chama atenção o fato, de no último subperíodo, sete das dez maiores contribuições terem sido de atividades que pertencem ao setor de serviços, enquanto na primeira fase apenas

(25) O encarecimento dos bens que seguem um preço de referência internacional, tanto como bens finais como através do consumo intermediário importado, responderam por 27,7\% da taxa de inflação em 2001-2003 (ou 3,68 p.p. ao ano), 17,5\% em 2004-2005 (ou 1,3 p.p. ao ano) e, 13,1\% em 2006-2009 (ou 0,79 p.p. ao ano).

(26) O CUT foi responsável por 23\% de toda a inflação brasileira em 2001-2003 (ou 3,05 p.p. ao ano), 34,2\% em 20042005 (ou 2,53 p.p. ao ano) e 47,5\% em 2006-2009 (ou 2,85 p.p. ao ano). A importância relativa da inflação salarial dobra no último subperíodo quando comparada ao primeiro. Esse resultado é compatível com o observado por Summa e Braga (2013). A partir de 2006, o processo de inflação salarial se intensifica na economia brasileira.

(27) O efeito das margens de lucro respondeu por 35,1\% da taxa de inflação em 2001-2003 (ou 4,66 p.p. ao ano), 38,9\% em 2004-2005 (ou 2,88 p.p. ao ano) e, 25,9\% em 2006-2009 (ou 1,55 p.p. ao ano)

(28) Vale destacar que esse movimento ocorreu concomitantemente à aceleração do crescimento da economia brasileira, sugerindo, que nos anos 2001-2009, as margens de lucro apresentaram um comportamento anticíclico. 
três contribuições eram oriundas do setor. A mudança maior na composição da lista das dez maiores de 2004-2005 para 2006-2009, comparativamente ao observado entre 2001-2003 e 2004-2005, sugere que a mudança de comportamento das variáveis distributivas e da contribuição de cada um dos efeitos para a taxa de inflação está diretamente associada à mudança de preços relativos na economia brasileira.

Chama especial atenção à entrada da atividade "Outros serviços" na lista das dez maiores. Essa atividade na Tabela de Recursos e Usos, divulgadas anualmente, é dividida em "Serviços prestados às famílias" e "Serviços domésticos". São atividades reconhecidamente influenciadas pelo comportamento do custo unitário do trabalho e com baixo crescimento da produtividade, ou seja, a evolução de seu preço está diretamente associada ao comportamento do salário nominal.

Indo além do período de análise desse trabalho, de 2010 a 2014, a economia brasileira passou a conviver com uma inflação salarial mais elevada que se materializou em uma inflação mais alta no setor de serviços (Braga; Summa, 2013). Isso sugere que a participação do setor na lista das dez maiores contribuições à taxa de inflação pode ter aumentado ainda mais e/ou a importância (magnitude) de suas contribuições pode ter crescido. Possivelmente, o setor símbolo desse processo, "Outros serviços", continuou subindo na lista de maiores contribuições à taxa de inflação.

Quadro 1

As dez maiores contribuições para a taxa de inflação em cada subperíodo por atividade

\begin{tabular}{|l|l|l|}
\hline \multicolumn{1}{|c|}{$2001-2003$} & \multicolumn{1}{|c|}{$2004-2005$} & \multicolumn{1}{c|}{$2006-2009$} \\
\hline Comércio (S) & Comércio (S) & Comércio (S) \\
\hline Alimentos e Bebidas (I) & Alimentos e Bebidas (I) & Alimentos e Bebidas (I) \\
\hline $\begin{array}{l}\text { Intermediação Financeira e Seguros } \\
\text { (S) }\end{array}$ & $\begin{array}{l}\text { Transporte, Armazenagem e } \\
\text { Correio (S) }\end{array}$ & Construção (I) \\
\hline $\begin{array}{l}\text { Transporte, Armazenagem e } \\
\text { Correio (S) }\end{array}$ & Serviços de Informação (S) & $\begin{array}{l}\text { Transporte, Armazenagem e } \\
\text { Correio (S) }\end{array}$ \\
\hline Refino de Petróleo e Coque (I) & Refino de Petróleo e Coque (I) & $\begin{array}{l}\text { Serviços Prestados às Empresas } \\
\text { (S) }\end{array}$ \\
\hline $\begin{array}{l}\text { Agricultura, Silvicultura e } \\
\text { Exploração Florestal (A) }\end{array}$ & Construção (I) & $\begin{array}{l}\text { Serviços Imobiliários e Aluguel } \\
\text { (S) }\end{array}$ \\
\hline Construção (I) & Fabricação de Aço e Derivados (I) & $\begin{array}{l}\text { Agricultura, Silvicultura e } \\
\text { Exploração Florestal (A) }\end{array}$ \\
\hline $\begin{array}{l}\text { Eletricidade e Gás, Água, Esgoto e } \\
\text { Limpeza Urbana (I) }\end{array}$ & Petróleo e Gás Natural (I) & $\begin{array}{l}\text { Serviços de Alojamento e } \\
\text { Alimentação (S) }\end{array}$ \\
\hline Serviços Prestados às Empresas (S) & $\begin{array}{l}\text { Eletricidade e Gás, Água, Esgoto e } \\
\text { Limpeza Urbana (I) }\end{array}$ & $\begin{array}{l}\text { Serviços de Informação (S) } \\
\text { (S) }\end{array}$ \\
\hline Fabricação de Aço e Derivados (I) & $\begin{array}{l}\text { Intermediação Financeira e Seguros } \\
\text { Outros Serviços (S) }\end{array}$ \\
\hline
\end{tabular}

Fonte: SCN/IBGE e Neves (2013). Elaboração própria. Legenda: A = Agropecuária, I = Indústria e S = Serviços. 


\section{A decomposição das margens de lucro dos bens com preço internacional}

Como já discutido, enquanto para os bens com preço doméstico, a evolução dos custos é crucial para determinar a dinâmica de preços; para os bens com preço internacional, a evolução dos custos é primordial na determinação das margens de lucro. A Tabela 3 mostra a contribuição que cada um dos efeitos apresentou sobre a margem de lucro dos bens que seguem um preço de referência internacional ao longo da década passada, obedecendo à divisão em três subperíodos. Todos os efeitos com sinal positivo contribuíram para a elevação das margens, enquanto todos os efeitos com sinal negativo contribuíram para a redução delas. Assim, os efeitos que elevaram o custo de produção aparecem com sinal negativo. Uma diferença importante em relação à decomposição da taxa de inflação exposta na Tabela 2, é que na decomposição das margens de lucro, os efeitos incluem apenas sua influência direta, a dimensão indireta não é contemplada. Na verdade, o efeito consumo intermediário absorve todo o impacto que a majoração dos custos nas etapas anteriores da cadeia produtiva exerceu. Todo o encarecimento dos insumos devido, por exemplo, ao encarecimento das importações, mudanças tributárias ou expansão do CUT nas etapas anteriores do processo produtivo estão dentro do efeito consumo intermediário.

A variação combinada do preço internacional $\left(\mathrm{P}^{*}\right)$ e da taxa nominal de câmbio (e) determina a evolução do preço no mercado interno. A variação do preço no mercado interno (e.P*) exerce uma contribuição para a elevação das margens de lucro. Como a dinâmica de preços não é determinada pelos custos de produção, podemos dizer que quanto maior o preço no mercado interno, maiores serão as margens. Podemos notar na Tabela 3 que a variação de preço, positiva ao longo de todo o período 2001-2009, promoveu contribuição positiva para a elevação das margens de lucro nos três subperíodos.

Ao observar a Tabela 3, podemos chegar a algumas constatações. A primeira é que por englobar todas as etapas anteriores do processo de produção, o principal efeito majorador dos custos de produção é sempre o efeito consumo intermediário. A evolução das margens é positiva nos dois primeiros subperíodos. Elas cresceram, em média, 20,04\% a.a. no primeiro triênio e 12,87\% a.a. em 2004-2005. Em 2006-2009, as margens de lucro caíram, em média, $1,67 \%$ ao ano. A desaceleração da inflação dos bens com preço internacional de $18,1 \%$ para $11,6 \%$ e, depois, $6,9 \%$ ao ano foi determinante para esse resultado, uma vez que os custos de produção pressionaram as margens de lucro cada vez menos ao longo da década. Isso pode ser observado também através da contribuição da variação de preços para a evolução das margens, de 168,12 p.p. em 2001-2003, 77,29 p.p. em 2004-2005 e 61,4 p.p. em 2006-2009. 
Tabela 3

Contribuições médias para a evolução das margens de lucro dos bens com preço internacional

\begin{tabular}{l|c|c|c}
\hline & $2001-2003$ & $2004-2005$ & $2006-2009$ \\
\hline Efeito Consumo Intermediário & $-113,97$ & $-35,45$ & $-41,27$ \\
\hline Insumos domésticos - Efeito preços relativos & $-6,88$ & $-11,65$ & $-3,73$ \\
\hline Insumos domésticos - Efeito volume relativo & 3,58 & $-3,98$ & $-0,05$ \\
\hline Insumos importados - Efeito volume relativo & 0,95 & 1,73 & $-1,36$ \\
\hline Insumos importados - Efeito preço & $-11,90$ & $-0,37$ & $-1,57$ \\
\hline Impostos sobre produtos - Efeito volume relativo & $-0,38$ & 0,70 & 0,48 \\
\hline Impostos sobre produtos - Efeito preço & $-5,04$ & $-2,67$ & $-2,45$ \\
\hline Outros Impostos e Subsídios & $-1,73$ & $-0,77$ & $-1,00$ \\
\hline Subtotal de Impostos & $-7,15$ & $-2,74$ & $-2,96$ \\
\hline Salário médio & $-8,39$ & $-6,39$ & $-9,50$ \\
\hline Produtividade do Trabalho & $-1,48$ & $-3,72$ & $-1,30$ \\
\hline Custo Unitário do Trabalho & $-9,87$ & $-10,10$ & $-10,80$ \\
\hline Rendimento Misto & $-0,52$ & $-0,04$ & $-0,11$ \\
\hline Termos de interação & $-2,31$ & $-1,80$ & $-1,22$ \\
\hline Total dos Custos de Produção & $-148,08$ & $-64,42$ & $-63,07$ \\
\hline Contribuição da Variação de Preços & 168,12 & 77,29 & 61,40 \\
\hline Variação das Margens de Lucro & 20,04 & 12,87 & $-1,67$ \\
\hline Fon SCN/IBGE e Neves (2013). Elaboçäo propr & & & \\
\hline
\end{tabular}

Fonte: SCN/IBGE e Neves (2013). Elaboração própria.

A evolução do CUT pressionou as margens de lucro cada vez mais ao longo do período. A influência do efeito salário médio foi crescente, resultado do crescimento do salário nominal cada vez mais acelerado nos setores produtores de bens com preço internacional. A produtividade do trabalho nesses setores caiu nos três subperíodos, pressionando as margens. Todavia, a queda menor no último quadriênio amenizou seu impacto negativo, compensando parcialmente os impactos do crescimento salarial mais acelerado. Vale ressaltar que a influência da expansão do custo da mão de obra nas etapas anteriores da cadeia produtiva está presente no efeito consumo intermediário.

O efeito preço do insumo intermediário importado exerceu uma pressão menor sobre as margens nos dois últimos subperíodos do que no primeiro, resultado análogo ao observado para os bens com preço doméstico, mesmo com a importante diferença de se tratar apenas do efeito direto. Isso está associado ao impacto sobre o custo de produção da taxa de câmbio e da cotação internacional.

De modo geral, as variáveis distributivas causadoras da majoração dos custos, e seus impactos sobre a dinâmica de preços e sobre as margens de lucro, apresentaram comportamento bastante semelhante ao longo da década nos dois grandes grupos em que a economia brasileira foi dividida nesse trabalho. 


\section{Conclusão}

A inflação brasileira apresentou comportamento bastante heterogêneo ao longo do período 2001-2009. A heterogeneidade não se expressou apenas na diferença entre as taxas observadas no começo da década para as do final, ela se expressou também nos fatores responsáveis pela majoração do nível de preços.

A decomposição estrutural realizada nesse trabalho alcançou o seu objetivo de separar e evidenciar a influência de cada elemento presente no custo de produção, assim como de estimar o impacto (magnitude) de cada um deles na dinâmica inflacionaria brasileira. Além de avaliar o comportamento das variáveis de custo, foi possível analisar o comportamento das margens de lucro para os bens que seguem um valor de referência internacional.

A partir dos resultados da decomposição estrutural, notamos que nos anos 2001-2003, o encarecimento dos bens com preço internacional pressionou sensivelmente os custos de produção. Mesmo com o comportamento ameno das commodities no cenário internacional, a desvalorização nominal da taxa de câmbio elevou a inflação brasileira. Os assalariados, tentando recuperar seu poder de compra através do aumento do salário nominal em um quadro de queda da produtividade do trabalho, elevaram o custo unitário do trabalho, o que pressionou ainda mais os custos de produção.

Nos anos 2004-2005, o comportamento de diversas variáveis começou a se alterar. Primeiro, a taxa de inflação se reduziu, assim como o impacto das commodities, mesmo em um quadro de crescimento mais acelerado da cotação das mesmas no mercado internacional. Foi o início de um expressivo processo de valorização da taxa nominal de câmbio. Junto a isso, a tentativa de recomposição das margens de lucro passou a pressionar menos o nível de preços. O custo unitário do trabalho reduziu sua contribuição à taxa de inflação. Porém, como a queda da taxa de inflação foi maior, a importância relativa do custo unitário do trabalho para explicar a inflação brasileira aumentou.

Nos anos 2006-2009, uma série de resultados iniciados em 2004-2005 foi intensificada. A taxa de inflação voltou a cair e a cotação dos bens com preço internacional em Real teve trajetória ainda mais suave do que na fase anterior. Novamente, esse resultado só foi possível graças à valorização nominal da taxa de câmbio, uma vez que a cotação das commodities continuou a aumentar na economia mundial. A contribuição promovida pela tentativa de recomposição das margens nominais de lucro foi a menor de todas as três fases e ajudou a reduzir a inflação brasileira. Mesmo a produtividade do trabalho moderando a evolução do custo unitário do trabalho, ele passou a contribuir mais para a taxa de inflação. Como a inflação voltou a cair, a importância relativa do custo unitário do trabalho voltou a aumentar. Pela primeira vez houve queda das margens de lucro nos setores com preço internacional.

Como elementos complementares, podemos destacar a importância relativa da tributação, que se manteve estável ao longo da década, e o comportamento dos coeficientes técnicos, que conteve a taxa de inflação nos primeiros anos e passou a pressionar os custos de produção no fim do período. 
Isso significa que a inversão do comportamento das margens de lucro nominais, somada à suavização da trajetória das commodities em moeda doméstica e ao crescimento da produtividade na última fase, foi forte o suficiente para conter o crescimento do salário nominal e dos custos de produção associado às técnicas produtivas em funcionamento no Brasil; reduzindo a inflação brasileira a menos da metade da observada para os três primeiros anos da série. A suavização do comportamento dos bens com preço internacional chama atenção especial por se tratar de um período que ficou conhecido como super ciclo das commodities na economia mundial e reforça a importância da taxa de câmbio na explicação da inflação brasileira nesse período.

Diretamente associada à mudança de comportamento das variáveis distributivas, está a mudança na composição das principais contribuições para a taxa de inflação brasileira por atividade. Enquanto nos anos 2001-2003 e 2004-2005, o setor de serviços possuía apenas quatro atividades entre as dez maiores contribuições, no período 2006-2009, sete das dez maiores contribuições pertenciam ao setor. Esse resultado é consequência do aumento de importância do custo unitário do trabalho na explicação da inflação brasileira.

\section{Bibliografia}

ALLAIN, O. Tackling the instability of growth: a Kaleckian-Harrodian model with an autonomous expenditure component. Cambridge Journal of Economics, v. 39, n. 5, p. 1351$1371,2015$.

AUKRUST, O. Inflation in the open economy: a Norwegian model. Oslo: Artikler, 1977.

BASTOS, C. P.; BRAGA, J. Conflito distributivo e inflação no Brasil: uma aplicação ao período recente. In: MACROECONOMIA para o desenvolvimento: crescimento, estabilidade e emprego. Rio de Janeiro: Editora IPEA, 2010. p. 119-156.

BARBOSA-FILHO, N. A structuralist inflation curve. Metroeconomica, p. 1-28, Mar. 2014.

BRAGA, J. Inflação no Brasil nos anos 2000: conflitos, limites e políticas não-monetárias. In: CARNEIRO, R.; MATIJASCIC, M. (Org.). Desafios do desenvolvimento brasileiro. Rio de Janeiro: Editora IPEA, 2011. p. 108-123.

BRAGA, J. A inflação brasileira na década de 2000 e a importância de políticas não monetárias de controle. Economia e Sociedade, v. 22, n. 3, p. 607-727, dez. 2013.

EDGREN, G. et al. Growth and the distribution of income. The Swedish Journal of Economics, v. 71, n. 3, p. 133-160, 1969.

FRISCH, H. The Scandinavian model of inflation: a generalization and empirical evidence. Atlantic Economic Journal, v. 5, n. 3, p. 1-14, dez. 1977.

FREITAS, F.; SERRANO, S. Growth rate and level effects, the stability of the adjustment of capacity to demand and the Sraffian supermultiplier. Review of Political Economy, v. 27, n. 3 , p. 258-281, 2015. 
FREITAS, F.; SERRANO, F. O supermultiplicador Sraffiano e o papel da demanda efetiva nos modelos de crescimento. Circus, Grupo Luján, Buenos Aires, v. 1, n. 1, 2007.

GOMES, L. S. A dinâmica inflacionária no Brasil de 2000 a 2009: uma abordagem multissetorial, Tese - IE, UFRJ, Rio de Janeiro, 2016. Disponível em: http://wits.worldbank.com/. Acesso em: 10 jan. 2015.

LAVOIE, M. Convergence towards the normal rate of capacity utilization in neo-kaleckian models: the role of non-capacity creating autonomous expenditures. Metroeconomica, v. 67, n. 1, p. 172-201, 2016.

LEWIS, A. O desenvolvimento econômico com oferta ilimitada de mão-de-obra. The Manchester School, 1954.

MARTINEZ, T. S.; CERQUEIRA, V. S. Estrutura da inflação brasileira, determinantes e desagregação do IPCA. Economia e Sociedade, v. 22, n. 2, p. 409-456, ago. 2013.

MEDEIROS, C. A.; SERRANO, F. Padrões monetários internacionais e crescimento. In: FIORI, L. (Org.). Estados e moedas no desenvolvimento das nações. Petrópolis: Editora Vozes, 1999. p. 119-151.

MEDEIROS, C. A. Inserção externa, exportações e crescimento no Brasil. In: FIORI, L.; MEDEIROS, C. A. (Org.). Polarização mundial e crescimento. Petrópolis: Editora Vozes, 2001. p. 105-134.

MILLER, R. E.; BLAIR, P. D. Input-output analysis: foundations and extensions. Cambridge: Cambridge University Press, 2009.

PIMENTEL, D. M.; LUPORINI; MODENESI, A. Assimetrias no repasse cambial para a inflação: uma análise empírica para o Brasil (1999 a 2013). Estudos Econômicos, v. 46, p. 343-372, 2016.

MODENESI, A. M. Política monetária e combate à inflação. In: EARP, F. S.; BASTIAAN, E. F.; MODENESI, A. N. (Org.). Como vai o Brasil? A economia brasileira no terceiro milênio. Rio de Janeiro: Imã Editorial, 2014, p. 1-279.

MODENESI, A.; ARAÚJO, E. C. Determinantes macroeconômicos da inflação: implicações para a política monetária. In: FERRARI-FILHO, F.; PAULA, L. F. (Org.). A crise financeira internacional: origens, desdobramentos e perspectivas. São Paulo: Unesp, 2012, p. 15-18.

NEVES, J. P. Mudança estrutural na economia brasileira entre os anos 2000-2008: uma análise de decomposição estrutural. Dissertação-IE. UFRJ, Rio de Janeiro, 2013.

PAULA, L. F. R.; SARAIVA, P. J. O regime de metas de inflação no Brasil: o que deve ser mudado? In: BELLUZZO, L. G.; BASTOS, P. P. Z. (Org.). Austeridade para quem? Balanço e perspectivas do Governo Dilma Rousseff. São Paulo: Carta Maior/Friedrich Ebert Stiftung, 2015, p. $155-163$. 
PREBISCH, R. O desenvolvimento econômico da América Latina e alguns de seus problemas principais. In: BIELSCHOWSKY, R (Org.). Cinqüenta anos de pensamento na Cepal. Rio de Janeiro: Record, 2000. v. 1, p. 69-136.

SERRANO, F. Long period effective demand and the Sraffian supermultiplier. Contributions to Political Economy, v. 14, p. 67-90, 1995a.

SERRANO, F. The Sraffian supermultiplier. Unpublished $\mathrm{PhD}$ Thesis, University of Cambridge, UK, 1995b.

SERRANO, F.; FREITAS, F. The Sraffian supermultiplier as an alternative closure to heterodox growth theory. European Journal of Economics and Economic Policies: Intervention, Edward Elgar Publishing, v. 14, n. 1, p. 70-91, Apr. 2017.

SERRANO, F.; SUMMA. R. Política econômica, crescimento e distribuição de renda na economia brasileira nos anos 2000. In: ENCONTRO INTERNACIONAL DA ASSOCIAÇÃO KEYNESIANA BRASILEIRA, 4, Rio de Janeiro, 2011. Anais...

SUMMA, R. Mercado de trabalho e evolução dos salários no Brasil. Rio de Janeiro: UFRJ. IE, 2014. (Texto para Discussão, n, 13).

SUMMA, R.; BRAGA, J. Taxa de juros, taxa de câmbio e inflação no período do sistema de metas de inflação no Brasil. In: CORREA, Vanessa Petrelli (Org.). Padrão de acumulação e desenvolvimento brasileiro. 1. ed. Perseu Abramo, 2013, p. 1-248. 